\title{
Ecohydrological effects of stream-aquifer water interaction: a case study of the Heihe River basin, northwestern China
}

\author{
Yujin Zeng ${ }^{1,2}$, Zhenghui Xie ${ }^{1}$, Yan Yu ${ }^{3}$, Shuang Liu ${ }^{1,2}$, Linying Wang ${ }^{1,2}$, Binghao Jia ${ }^{1}$, Peihua Qin ${ }^{1}$, and Yaning Chen ${ }^{4}$ \\ ${ }^{1}$ State Key Laboratory of Numerical Modeling for Atmospheric Sciences and Geophysical Fluid Dynamics, Institute of \\ Atmospheric Physics, Chinese Academy of Sciences, Beijing, 100029, China \\ ${ }^{2}$ College of Earth Science, University of Chinese Academy of Sciences, Beijing, 100049, China \\ ${ }^{3}$ Zhejiang Institute of Meteorological Sciences, Hangzhou, 310008, China \\ ${ }^{4}$ Key Laboratory of Oasis Ecology and Desert Environment, Xinjiang Institute of Ecology and Geography, Chinese Academy \\ of Sciences, Urumqi, 830011, China \\ Correspondence to: Zhenghui Xie (zxie@lasg.iap.ac.cn)
}

Received: 7 January 2016 - Published in Hydrol. Earth Syst. Sci. Discuss.: 19 January 2016

Accepted: 29 May 2016 - Published: 16 June 2016

\begin{abstract}
A scheme describing the process of streamaquifer interaction was combined with the land model CLM4.5 to investigate the effects of stream water conveyance over riparian banks on ecological and hydrological processes. Two groups of simulations for five typical river cross sections in the middle reaches of the arid-zone Heihe River basin were conducted. The comparisons between the simulated results and the measurements from water wells, the FLUXNET station, and remote sensing data showed good performance of the coupled model. The simulated riparian groundwater table at a propagation distance of less than $1 \mathrm{~km}$ followed the intra-annual fluctuation of the river water level, and the correlation was excellent $\left(R^{2}=0.9\right)$ between the river water level and the groundwater table at the distance $60 \mathrm{~m}$ from the river. The correlation rapidly decreased as distance increased. In response to the variability of the water table, soil moisture at deep layers also followed the variation of river water level all year, while soil moisture at the surface layer was more sensitive to the river water level in the drought season than in the wet season. With increased soil moisture, the average gross primary productivity and respiration of riparian vegetation within $300 \mathrm{~m}$ from the river in a typical section of the river increased by approximately 0.03 and $0.02 \mathrm{mg} \mathrm{C} \mathrm{m}^{-2} \mathrm{~s}^{-1}$, respectively, in the growing season. Consequently, the net ecosystem exchange increased by approximately $0.01 \mathrm{mg} \mathrm{m}^{-2} \mathrm{~s}^{-1}$, and the evapotranspiration increased by approximately $3 \mathrm{~mm} \mathrm{day}^{-1}$. Furthermore, the length of the growing season of riparian vegeta-
\end{abstract}

tion also increased by $2-3$ months due to the sustaining water recharge from the river. Overall, the stream-aquifer water interaction plays an essential role in the controlling of riparian hydrological and ecological processes.

\section{Introduction}

Water is indispensable for ecohydrological system (Milly et al., 2005; Ouyang et al., 2003; Shen and Chen, 2010; Zhao and Cheng, 2002). Among a variety of water resources, aquifer water and stream water, which constitute more than $30 \%$ of the freshwater storage, are key factors in hydrological cycle (Chen and Xie, 2010; Schär et al., 1999; Xie et al., 2014; Yu et al., 2014). The aquifer water usually acts as a water buffer reservoir to the ecological and hydrological system (Fan, 2015; Tsur and Graham-Tomasi, 1991). In the humid season, aquifer water can store the excess rainfall, and in the arid season, it reversely recharges the wet, root-zone soil and sustains the ecosystem above by upward capillary flux (Nepstad et al., 1994). The stream is also very important in the ecohydrological system. It continuously transports water from the humid region to the arid region and supports the ecosystem in the lower-reach area (Contreras et al., 2011; Jobbagy et al., 2011).

The relationship between water in streams and aquifers is close and both resources have important roles in the carbonwater cycle and in supplying human needs (Chen and Xie, 
2010, 2012; Yu et al., 2014; Zou et al., 2014, 2015; Xie et al., 2014). In a wet region, rainfall or melting snow can raise the groundwater table to an elevation higher than that of the vicinal stream level, and groundwater can sustain base flow in streams and rivers (Arnold et al., 2000). In an arid region, groundwater is recharged laterally from rivers to unconfined aquifers by the stream water conveyance, which sustains the terrestrial ecosystem along the natural channel (Scanlon et al., 2002; Chen et al., 2004, 2010) and induces an increase of riparian soil moisture, soil evaporation, and vegetation transpiration. The growth of riparian vegetation and subsequently changes in carbon cycle processes respond to the water supplement of streams. Understanding and quantifying the effects of stream water conveyance over riparian banks on ecological and hydrological processes is of significance for water resource management (Baskaran et al., 2009).

To investigate the interaction between groundwater and climate, Liang et al. (2003) and Liang and Xie (2003) presented a new parameterization to represent surface and groundwater dynamics and implemented it into the variable infiltration capacity model. Studies have documented that the interaction between surface water and groundwater significantly affects the partition of the water budget and then the land-atmosphere interaction (Maxwell et al., 2007; Maxwell and Kollet, 2008; Fan and Miguez-Macho, 2010, 2011; Fan, 2015). To predict the water table elevation near a river channel in an arid region from river discharge, Xie and Yuan (2010) developed a statistical-dynamical approach, whereas Di et al. (2011) and Xie et al. (2012) each developed a quasi-two-dimensional and quasi-three-dimensional variably saturated groundwater flow model. These works focused on the temporal and spatial variation of the groundwater table and soil moisture in a riverbank. However, the impacts of river-aquifer water exchange on ecological and hydrological processes, including energy and vapor fluxes, gross primary productivity (GPP), and net ecosystem exchange (NEE) for the riparian ecosystem are not fully represented in previous research. In this study, a scheme for stream-aquifer water interaction was combined with the Community Land Model Version 4.5 (CLM4.5), which contains descriptions about the energy, biophysical, and biochemical processes of the land surface and subsurface, to investigate the effects of streamaquifer interaction over five cross sections in the middle reaches of the Heihe River basin, a typical region that has an arid climate. Overall, the objectives of the study are (1) combining the scheme of stream-aquifer interaction and the land model CLM4.5; (2) quantifying the magnitudes of the responses of the riparian hydrological and ecological processes to the stream-aquifer water interaction; (3) quantifying the maximum distance that the stream water lateral flow can affect along the riverbank; and (4) studying the relationship between the magnitude of the effects and the distance to river.

In Sect. 2 of this paper, the model description about the stream-aquifer interaction scheme and CLM4.5 are specifically described, while some background information about the study domain and the experimental design are described in Sect. 3. Section 4 contains the results of simulations and the corresponding analysis. The conclusions and discussion are presented in Sect. 5 .

\section{Model description}

\subsection{Community Land Model 4.5}

The land surface model CLM4.5 was developed by the National Center for Atmospheric Research (Oleson et al., 2013), and is the land component of the Community Earth System Model 1.2.0 (Gent et al., 2011; Hurrell et al., 2013). The CLM4.5 model simulates the biogeophysical exchange of radiation, sensible, and latent heat flux; momentum between the land and atmosphere as modified by vegetation and soil; heat transfer in soil and snow; and the hydrologic cycle including precipitation interception, infiltration, runoff, soil water, groundwater table depth, and snow dynamics (Lindsay et al., 2014). Biogeochemical cycles including processes of the carbon and nitrogen cycles, photosynthesis, vegetation phenology, decomposition, and fire disturbances are also presented in CLM4.5. Evapotranspiration simulated by CLM4.5 is partitioned into evaporation and transpiration regulated by stoma physiology and photosynthesis. Specifically, in the CLM4.5 a non-linear groundwater reservoir model is used, but it is basically a onedimensional model which only explicitly accounts the vertical recharge from soil layer to aquifer on the dynamics of the groundwater table. Though a subsurface runoff scheme is applied, it does not explicitly solve the lateral flow and is only suitable in the large-scale modeling. More information about CLM4.5 is contained in the Journal of Climate (http://journals.ametsoc.org/page/CCSM4/CESM1).

\subsection{Configuration of CLM4.5 for simulation over riverbanks}

Generally CLM4.5 is used for large-scale simulations (global/continental) using relatively coarse grid resolution (about $0.1-1^{\circ}$ ), and these simulations usually make use of a horizontal 2-D grid structure. However, in the investigation of the effects of stream-aquifer water interaction over riverbanks (especially the intensities of these effects with different distances to river), only the one-dimensional direction perpendicular to the river is matter. Furthermore, the spatial scale of the stream-aquifer interaction is usually restricted within several hundred meters. So some special modifications and configurations should be conducted to make the model suitable for the one-dimensional and fine-scale simulation.

As an example, to a certain cross section, we first made the one-dimensional surface data set used in CLM4.5 simulation for the riverbank using surface-data-generated tool (Kluzek 2012). The schematic diagram for these one-dimensional 
grids of the surface data set was shown in Fig. 1c. At this time, the longitude and latitude values of each grid were set arbitrarily because they would be modified later. Then we changed the longitude and latitude of each grid to make them represent the real location of each site over the riverbank. Next, we replaced each grid's elevation, terrain slope, maximum fractional saturated area, land cover type (bare ground, vegetation, lakes, etc.), and soil type (percentage of clay, silt, sand, and soil organic matter) of the surface data set with the high-resolution ASTER DEM data set (Hirano et al., 2003; Li et al., 2011), MICLCover (Ran et al., 2012), HiWATER Land Cover Map (Li et al., 2013), and the China soil characteristics data set (Shangguan et al., 2012). At last, the subsurface runoff scheme in CLM4.5 was turned off because it was not suitable in the fine-scale modeling and would be replaced by the groundwater lateral flow in stream-aquifer interaction scheme (described in the Sect. 2.3, which was the explicit representation of the subsurface process). All the vertical biogeophysical and biogeochemical processes of CLM4.5 were retained because they were not scale-dependent and could be used in any resolution if the corresponding surface data set was set properly.

\subsection{Scheme for stream-aquifer interaction and its implementation into CLM4.5}

The stream-aquifer water interaction scheme (including groundwater lateral flow), developed by Di et al. (2011), was combined with CLM4.5 (the combined model was called CLM_RIV). We first describe the new model briefly as follows. Based on Darcy's law and the Dupuit approximation (Bear, 1972), the lateral flow between a river and the neighboring groundwater can be expressed as

$R(x, t)=\frac{\partial Q}{\partial x}=\frac{\partial}{\partial x}\left(T(x, t) \frac{\partial h(x, t)}{\partial x}\right), x>0, t \geq 0$,

while the corresponding initial and boundary conditions are expressed as

$h(x, 0)=h_{0}(x)$,

$h(0, t)=h_{\text {river }}(t)$,

where $x(\mathrm{~L})$ is the perpendicular distance from the point on a bank to the river channel, $t(\mathrm{~T})$ is time, $R(x, t)\left(\mathrm{L} \mathrm{T}^{-1}\right)$ is the lateral groundwater recharge (or discharge) rate at point $x$ and time $t, Q\left(\mathrm{~L}^{2} \mathrm{~T}^{-1}\right)$ is the lateral flow discharge, $T(x, t)$ $\left(\mathrm{L}^{2} \mathrm{~T}^{-1}\right)$ is the lateral flow transmissivity, $h(x, t)(\mathrm{L})$ is the groundwater table elevation, $h_{0}(x)(\mathrm{L})$ is the initial groundwater table elevation, and $h_{\text {river }}(t)$ (L) is the river water level, as shown in Fig. 1a and b. If the river water level is higher in elevation than its neighboring groundwater table (as shown in Fig. 1a), $R(x, t)$ is greater than zero and the local aquifer is recharged by the stream; otherwise, as shown in Fig. 1b, $R(x, t)$ is less than zero and the local aquifer discharges to the stream.
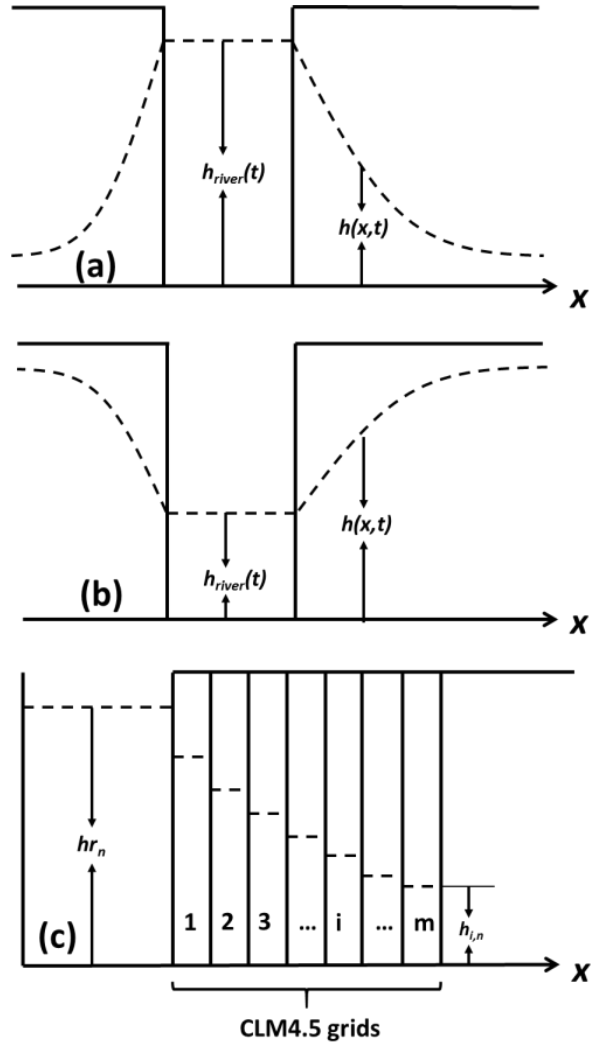

Figure 1. Schematic representation of stream-aquifer water interaction when (a) the river water level is higher than its neighboring groundwater table and (b) the river water level is lower than its neighboring groundwater table. (c) Schematic diagram for horizontal discrete grid cells of a riverbank. The dashed lines represent the water heads.

To combine the stream-aquifer interaction scheme with CLM4.5, the continuity Eq. (1) should be discretized over the one-dimensional grids of the surface data set of CLM4.5 (Fig. 1c). Applying the zero-flux boundary condition to the outermost grid of the simulation domain, the discrete formation of Eq. (1) can be written as

$$
\left\{\begin{array}{l}
R_{1, n}=\frac{\frac{T_{0, n}+T_{1, n}}{2} \times \frac{h_{r n}-h_{1, n}}{\Delta x / 2}}{R_{i, n}}=\frac{\frac{\frac{T_{1, n}+T_{2, n}}{2} \times \frac{h_{1, n}-h_{2, n}}{\Delta x} \Delta x}{2 x} \times \frac{h_{i-1, n}-h_{i, n}}{\Delta x}}{2 x}-\frac{\frac{T_{i, n}+T_{i+1, n}}{2} \times \frac{h_{i, n}-h_{i+1, n}}{\Delta x}}{\Delta x}, 2 \leq i \leq m-1 \\
R_{m, n}=\frac{\frac{T_{m-1, n}+T_{m, n}}{2} \times \frac{h_{m-1, n}-h_{m, n}}{\Delta x}}{\Delta x}
\end{array},\right.
$$

where $i$ is the number of the grid that is successively added with the increasing distance from grid to channel (Fig. 1c), $m$ is the farthest grid from the river channel in the model (i.e., the outermost grid of the simulation domain), $n$ is the number of the time step, $R_{i, n}\left(\mathrm{~L} \mathrm{~T}^{-1}\right)$ is the lateral groundwater recharge (or discharge) rate of grid $i$ at the $n$th time step, $T_{i, n}\left(\mathrm{~L}^{2} \mathrm{~T}^{-1}\right)$ is the lateral flow transmissivity, $h_{i, n}(\mathrm{~L})$ is the groundwater table elevation, $h_{r n}(\mathrm{~L})$ is the river water level (which is another boundary condition of the simulation and 
will be discussed in Sect. 3.2), and $\Delta x(\mathrm{~L})$ is the side length of each model grid.

The variables $h_{i, n}, T_{i, n}$, and $R_{i, n}(i>0)$ in Eq. (4) are linked to CLM4.5 as follows. The water table elevation $h_{i, n}$ is easily obtained by subtracting the groundwater table depth from the ground elevation:

$h=h_{\mathrm{e}}-z_{\mathrm{wt}}$,

where $h_{\mathrm{e}}(\mathrm{L})$ and $z_{\mathrm{wt}}(\mathrm{L})$ are, respectively, the ground elevation and current groundwater table depth of the grid calculated by CLM4.5. To obtain the lateral flow transmissivity $T_{i, n}$, we considered two cases in the model. In case A, the groundwater table is within the soil layers of the model (i.e., water table lies within $3.8 \mathrm{~m}$ from surface) and the transmissivity can be expressed as

$$
T=T_{1}+T_{2},
$$

$T_{1}=\left\{\begin{array}{ll}K_{i} \times\left(z_{h, i}-z_{\mathrm{wt}}\right)+\sum_{j=i+1}^{10} K_{j} \Delta z_{j}, & i<10 \\ K_{10} \times\left(z_{h, 10}-z_{\mathrm{wt}}\right), & i=10\end{array}\right.$,

$T_{2}=\int_{0}^{\infty} K\left(z^{\prime}\right) \mathrm{d} z^{\prime}=\int_{0}^{\infty} K_{10} e^{-\frac{z^{\prime}}{f}} \mathrm{~d} z^{\prime}=K_{10} f$,

where $T_{1}\left(\mathrm{~L}^{2} \mathrm{~T}^{-1}\right)$ and $T_{2}\left(\mathrm{~L}^{2} \mathrm{~T}^{-1}\right)$ are, respectively, the lateral flow transmissivity within and outside the 10th soil layers of CLM4.5, $j$ is the number of soil layer denoted by CLM4.5, $K_{j}\left(\mathrm{~L} \mathrm{~T}^{-1}\right)$ and $f(\mathrm{~L})$ are, respectively, the lateral hydraulic conductivity of the $j$ th soil layer and the $e$-folding length (which will be discussed later), $\Delta z_{j}(\mathrm{~L})$ is the thickness of the $j$ th soil layer, $i$ is the soil layer where the groundwater table lies, $z_{h, i}(\mathrm{~L})$ is the lower boundary depth of the $i$ th soil layer, $z^{\prime}(\mathrm{L})$ is the relative depth to the bottom boundary of the 10th soil layer (where $z^{\prime}=z-3.8, z>3.8 \mathrm{~m}$ ), and $K\left(z^{\prime}\right)\left(\mathrm{L} \mathrm{T}^{-1}\right)$ is the lateral hydraulic conductivity at relative depth $z^{\prime}$. Based on Fan et al. (2007), we also applied an estimation of the lateral hydraulic conductivity at depth below the 10th soil layer in Eq. (8):

$K\left(z^{\prime}\right)=K_{10} e^{-\frac{z^{\prime}}{f}}$.

In CLM4.5, only the vertical hydraulic conductivity is provided. So to obtain the lateral hydraulic conductivity $K_{j}$ of each soil layer, we applied the assumption of Fan et al. (2007) such that the lateral conductivity is related to the vertical hydraulic conductivity and the content of clay for local soil:

$K_{j}=K_{j}^{\prime} \times P_{\text {clay }}$,

where $K_{j}^{\prime}\left(\mathrm{L} \mathrm{T}^{-1}\right)$ is the vertical hydraulic conductivity provided by CLM4.5 and $P_{\text {clay }}$ is the percentage of clay in local soil, as provided by surface data of CLM4.5. The $e$-folding length $f$ in Eq. (8) is a parameter representing the local sediment-bedrock profile, which is complex depending on tectonics, weathering and erosion-deposition processes. In this study, we simply implemented an estimation of Fan et al. (2007) to relate $e$-folding length to terrain slope:

$f=\left\{\begin{array}{ll}\frac{20}{1+125 \beta}, & \beta \leq 0.16 \\ 1, & \beta>0.16\end{array}\right.$,

where $\beta$ (radian) represents the terrain slope and can be obtained from the surface data of CLM4.5.

In case $\mathrm{B}$, where the groundwater table is positioned below the 10th soil layer of CLM4.5, the $T_{i, n}$ can be calculated as

$T=\int_{z_{\mathrm{wt}}-3.8}^{\infty} K\left(z^{\prime}\right) \mathrm{d} z^{\prime}=\int_{z_{\mathrm{wt}}-3.8}^{\infty} K_{10} e^{-\frac{z^{\prime}}{f}} \mathrm{~d} z^{\prime}=K_{10} f e^{\frac{3.8-z_{\mathrm{wt}}}{f}}$.

We also applied the parameterization of Eq. (9) in Eq. (12).

In Eq. (4), $T_{0, n}\left(\mathrm{~L}^{2} \mathrm{~T}^{-1}\right)$ is the flow transmissivity of the river with respect to the groundwater-river exchange. Based on Xie and Yuan (2010), flow transmissivity can be expressed as

$T_{0}=K_{\mathrm{r}} w$,

where $w(\mathrm{~L})$ is the river width obtained from measured data and $K_{\mathrm{r}}\left(\mathrm{L}^{2} \mathrm{~T}^{-1}\right)$ is the hydraulic conductivity at the riverbed (which will be discussed in Sect. 3.2).

Finally, the lateral water recharge (or discharge) rate $R_{i, n}$ in Eq. (4) is linked to CLM4.5 as follows:

$\left\{\begin{array}{l}z_{\mathrm{wt} \_ \text {new }}=z_{\mathrm{wt} \_ \text {ori }}-\frac{R \times \Delta t}{s_{\mathrm{y}}} \\ W_{\text {new }}=W_{\text {ori }}+R \times \Delta t\end{array}\right.$,

where $\Delta t(\mathrm{~T})$ is the time step of CLM4.5, $s_{\mathrm{y}}$ is the aquiferspecific yield calculated by CLM4.5, $z_{\mathrm{wt} \_o r i}(\mathrm{~L})$ and $z_{\mathrm{wt} \_ \text {new }}$ (L) are, respectively, the original simulated the groundwater table depth by CLM4.5 and the updated value after considering the later flow flux, and $W_{\text {ori }}(\mathrm{L})$ and $W_{\text {new }}(\mathrm{L})$ are, respectively, the original simulated aquifer water storage by CLM4.5 and the updated value after considering the lateral flow flux.

Equations (4)-(14) are applied in CLM4.5 to renew the values of the groundwater table depth and aquifer water storage at every time step. Other hydrological and ecological variables will be in turn be modified by these changes as the model continues to operate.

Besides the hydrological and ecological processes, the thermal processes of soil and ground are also affected by the stream-aquifer water interaction. In CLM4.5, the ground and soil heat transfer algorithm is applied on the vertical direction:

$c \frac{\partial T}{\partial t}=\frac{\partial}{\partial z}\left[\lambda \frac{\partial T}{\partial z}\right]$, 
Table 1. The locations and relevant information about the five selected sections used in simulations.

\begin{tabular}{llllrlll}
\hline $\begin{array}{l}\text { Number } \\
\text { of section }\end{array}$ & Name & Latitude & Longitude & $\begin{array}{c}\text { Width } \\
(\mathrm{m})\end{array}$ & $\begin{array}{l}\text { Riverbank } \begin{array}{l}\text { Bottom } \\
\text { elevation } \\
(\mathrm{m})\end{array} \\
\text { elevation } \\
(\mathrm{m})\end{array}$ & $\begin{array}{l}\text { Flow } \\
\text { direction }\end{array}$ \\
\hline 1 & 213 Bridge & $38^{\circ} 54^{\prime} 43.55^{\prime \prime} \mathrm{N}$ & $100^{\circ} 20^{\prime} 41.05^{\prime \prime} \mathrm{E}$ & 330 & 1493.1 & 1488.8 & Northeast \\
2 & 312 Bridge & $38^{\circ} 59^{\prime} 51.71^{\prime \prime} \mathrm{N}$ & $100^{\circ} 24^{\prime} 38.76^{\prime \prime} \mathrm{E}$ & 70 & 1402 & 1397 & Northeast \\
3 & Tielu Bridge & $39^{\circ} 2^{\prime} 33.08^{\prime \prime} \mathrm{N}$ & $100^{\circ} 25^{\prime} 49.42^{\prime \prime} \mathrm{E}$ & 50 & 1382 & 1379.25 & Northeast \\
4 & Pingchuan Bridge & $39^{\circ} 20^{\prime} 2.03^{\prime \prime} \mathrm{N}$ & $100^{\circ} 5^{\prime} 49.63^{\prime \prime} \mathrm{E}$ & 130 & 1323.8 & 1319 & West \\
5 & Gaotai Bridge & $39^{\circ} 23^{\prime} 22.93^{\prime \prime} \mathrm{N}$ & $99^{\circ} 49^{\prime} 37.29^{\prime \prime} \mathrm{E}$ & 210 & 1295.5 & 1288.5 & West \\
\hline
\end{tabular}

where $z(\mathrm{~L})$ is in the vertical direction and is positive downward, $T(\mathrm{~K})$ is the temperature, $c\left(\mathrm{~J} \mathrm{~L}^{-3} \mathrm{~K}^{-1}\right)$ is the volumetric soil heat capacity, $\lambda\left(\mathrm{W} \mathrm{L} \mathrm{L}^{-1} \mathrm{~K}^{-1}\right)$ is the thermal conductivity, and $t(\mathrm{~T})$ is time. The upper (surface) boundary condition of Eq. (15) is obtained from radiation calculation of CLM4.5, and the lower boundary condition is set as a zeroflux situation. Both the thermal properties of $c$ and $\lambda$ depend on the soil water content as follows (assuming no soil ice for concise expression):

$c=c_{\mathrm{s}}\left(1-\theta_{\mathrm{sat}}\right)+c_{\mathrm{liq}} \theta_{\mathrm{liq}}$,

$\lambda=K e \lambda_{\mathrm{sat}}+(1-K e) \lambda_{\mathrm{dry}}$,

$K e=\lg \left(\frac{\theta_{\text {liq }}}{\theta_{\text {sat }}}\right)+1$,

where $c_{\mathrm{S}}\left(\mathrm{J} \mathrm{L}^{-3} \mathrm{~K}^{-1}\right)$ and $c_{\text {liq }}\left(\mathrm{J} \mathrm{L}^{-3} \mathrm{~K}^{-1}\right)$ are, respectively, the heat capacity of soil solids and liquid water, $\theta_{\text {sat }}\left(\mathrm{L}^{3} \mathrm{~L}^{-3}\right)$ and $\theta_{\text {liq }}\left(\mathrm{L}^{3} \mathrm{~L}^{-3}\right)$ are, respectively, the saturated soil moisture and current soil liquid water content, $\lambda_{\text {sat }}\left(\mathrm{W} \mathrm{L}^{-1} \mathrm{~K}^{-1}\right)$ and $\lambda_{\text {dry }}\left(\mathrm{W} \mathrm{L}^{-1} \mathrm{~K}^{-1}\right)$ are, respectively, the saturated thermal conductivity and dry thermal conductivity, and $K_{e}$ is the Kersten number. More detailed information about the heat transfer calculation can be found in the Chapter 6 of technical description of CLM4.5 (Oleson et al., 2013). As shown by Eqs. (15)-(18), soil moisture $\theta_{\text {liq }}$ impacted by stream-aquifer water interaction would indirectly affect the simulated temperature and the other thermodynamic variables. Currently, the river temperature and the horizontal heat transfer are not included, but will be incorporated into our model in the future.

\section{Study domain and experimental design}

\subsection{Study domain}

The Heihe River basin is the second largest inland river basin in an arid area in northern China. It is located between $96^{\circ} 42^{\prime}$ and $102^{\circ} 00^{\prime} \mathrm{E}$ and between $37^{\circ} 41^{\prime}$ and $42^{\circ} 42^{\prime} \mathrm{N}$ (Lu et al., 2003) (Fig. 2). The basin covers $116000 \mathrm{~km}^{2}$ and lies to the east of the Shule River basin and west of the Shiyan River basin (Chen et al., 2005). In the upper reaches of the basin with obvious vertical zonal divisions, the mean annual

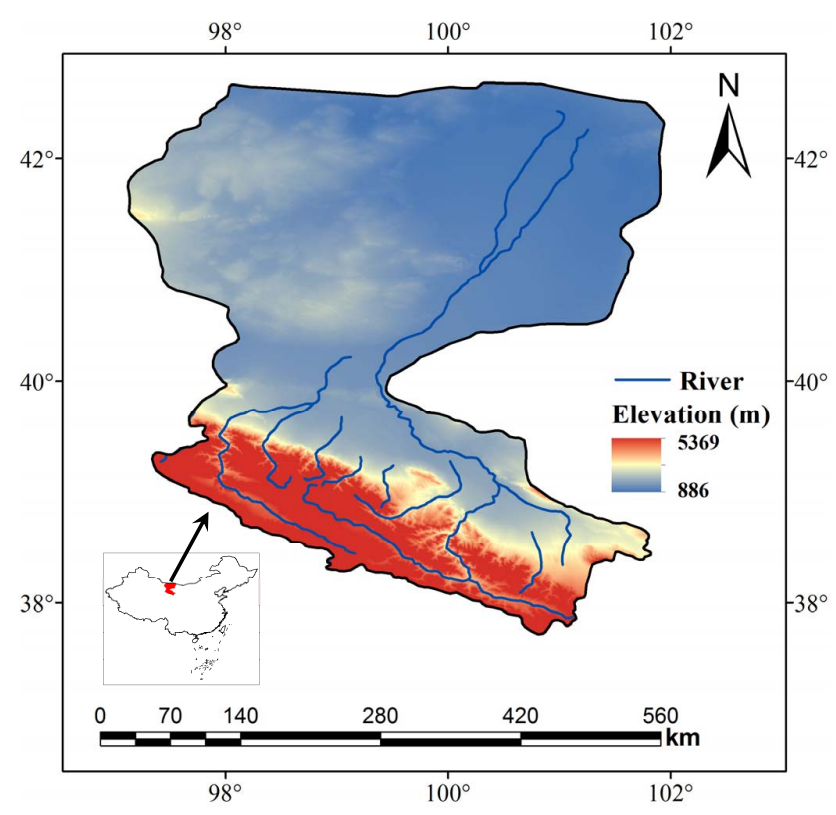

Figure 2. Study area and location of the Heihe River basin in northwest China.

precipitation is approximately $200 \mathrm{~mm}$ at elevations from 2000 to $3200 \mathrm{~m}$, and about $500 \mathrm{~mm}$ at elevations between 3200 and $5500 \mathrm{~m}$. The upper reaches are the main water resource of the entire basin ( $\mathrm{Wu}$ et al., 2010). In the middle reaches, the elevation decreases from 2000 to $1000 \mathrm{~m}$ and the precipitation correspondingly decreases from $200 \mathrm{~mm}$ to less than $100 \mathrm{~mm}$ in the direction from south to north ( $\mathrm{Li}$ et al., 2001). The lower reaches, whose mean altitude is approximately $1000 \mathrm{~m}$, are an arid region with a mean annual precipitation of only $42 \mathrm{~mm}$ according to statistics from meteorological stations (Qi and Luo, 2005).

In this study, five typical river cross sections were chosen as test sites to simulate using our CLM_RIV model. These sites were named, respectively, 213 Bridge, 312 Bridge, Tielu Bridge, Pingchuan Bridge, and Gaotai Bridge, and all are located on the middle reaches of the Heihe River basin. Among these sites, the 213 Bridge section was chosen to test the model's sensitivity, but all the five cross sections were used in the actual model runs. The locations of these sections and 


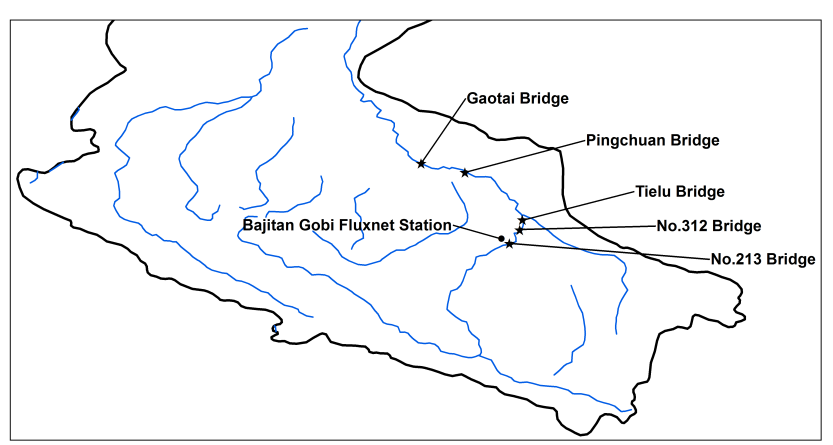

Figure 3. Locations of the five sections in the middle reaches of the Heihe River that were used for simulations and the location of Bajitan Gobi FLUXNET station that was used for validation.

relevant information about them are shown in Fig. 3 and Table 1 , respectively.

\subsection{Experimental design}

Some ideal experiments to test the model sensitivity to river water level and riverbed water conductivity were established for the 213 Bridge section. The CLM_RIV model was run at this section to simulate a riparian zone within $3000 \mathrm{~m}$ of the southeast riverbank using a horizontal resolution of $60 \mathrm{~m}$. The simulation period covered the whole year of 2012 using a time step of $1800 \mathrm{~s}$. The atmospheric forcing data were obtained from the China Meteorological Administration Land Data Assimilation System (CLDAS) and developed by the National Meteorological Information Center (NMIC). This high-quality data set combines field observations, remote sensing data, and numerical products at a horizontal resolution of $0.0625^{\circ}$. Initial conditions for the simulation were obtained from a 700-year spin-up run conducted using the original version of CLM4.5 (without the groundwater lateral flow) and cyclically using the CLDAS data set. The choice of 700 spin-up years was based on the user's guide of CLM (Ch. 4 of Kluzek, 2012) showing that when the biogeochemistry carbon-nitrogen module of CLM is turned on, the model should at least run for 700 years to get a steady state because the magnitudes of carbon and nitrogen fluxes are very small (Oleson et al., 2013). For each situation (case (a): the river recharging the groundwater, and case (b): the groundwater recharging the river) we conducted two sensitivity experiments. The first of these examined the sensitivity of the model predictions to changes in the river water level. Four constant river elevations were considered; in case (a) the four river elevations were $h_{\mathrm{r}}=1493.1,1492.1,1491.1$, and $1490.1 \mathrm{~m}$; and in case (b) the four river elevations were $h_{\mathrm{r}}=1483.1,1478.1,1473.1$, and $1468.1 \mathrm{~m}$. The hydraulic conductivity of the riverbed $\left(K_{\mathrm{r}}\right)$ was fixed at $7.4 \mathrm{~m}$ day $^{-1}$ for both cases. The second experiment tested the sensitivity of the model to changes in the hydraulic conductivity of the riverbed. In this experiment, the boundary condition of the river water level was fixed at $h_{\mathrm{r}}=1491.1 \mathrm{~m}$ in case (a) and $h_{\mathrm{r}}=1478.1 \mathrm{~m}$ in case (b). The four sets of river hydraulic conductivities were given as $K_{\mathrm{r}}=3,6,12$ and $24 \mathrm{~m}_{\text {day }}{ }^{-1}$ both for cases.

Then, to investigate the ecohydrological effects of streamaquifer interaction, a realistic simulation and a control simulation using CLM_RIV were conducted. The realistic simulation (called TEST) reproduced processes of stream-aquifer interaction and the groundwater lateral flow; the control simulation (called CTL) did not take the stream-aquifer interaction into consideration (assuming no water flux between the stream and riverbank as a boundary condition) but accounted for the groundwater lateral flow over the riverbank. For the river grid cells in the middle of each section, no simulations with CLM4.5 were performed. Each simulation covered a period of an entire hydrological year from 1 July 2012 to 30 June 2013 using a time step of 1800 s. The models were run at the five sections to simulate both sides of the river within a distance of $3000 \mathrm{~m}$ from the river channel using a horizontal resolution of $60 \mathrm{~m}$. As with the sensitivity tests, atmospheric forcing data were used from CLDAS as developed by NMIC. However, instead of using the default surface data set of CLM4.5 (Oleson et al., 2013), we replaced the data of elevation, terrain slope maximum and fractional saturated area with the ASTER DEM data set $(30 \mathrm{~m}$ resolution, Hirano et al., 2003; Li et al., 2011), land cover data with MICLCover (1 km resolution, Ran et al. 2012), plus HiWATER Land Cover Map (30 m resolution, Li et al., 2013), and soil data with the China soil characteristics data set $(1 \mathrm{~km}$ resolution, Shangguan et al., 2012). The soil types and vegetation types over both sides of the selected sections are shown in Table 2. Other model parameters, such as the parameters related to atmospheric boundary layer, hydrology, thermodynamics and vegetation (including root length density), were set as the default settings of CLM4.5. Detailed information about these parameters could be found in the technical description of CLM4.5 (Oleson et al., 2013).

In the TEST and CTL simulations using CLM_RIV, the lateral hydraulic conductivity of riverbed $\left(K_{\mathrm{r}}\right)$ was set to $7.4 \mathrm{~m} \mathrm{day}^{-1}$ based on research of Xie and Yuan (2010). The boundary conditions of river water levels $\left(h_{\mathrm{r}}\right)$ for the five sections were obtained from the data set of the hydrometeorological observation network, which is operated by Heihe Watershed Allied Telemetry Experimental Research (HiWATER, Li et al., 2013; Liu et al., 2014). The observations covered all time periods of our simulations with a time interval of $1800 \mathrm{~s}$. First, the TEST and CTL were started from the default initial condition of CLM4.5 (seen in Oleson et al., 2013) and run for 700 years under each configuration (with and without stream-aquifer water interaction), cyclically using the atmospheric forcing and observed water level data. Then, the TEST and CTL would start their formal runs from 1 July 2012 to 30 June 2013 using the restart files produced by the former 700 -year spin-up runs. 
Table 2. The soil types and vegetation types over both sides of the five selected sections used in simulations.

\begin{tabular}{llllll}
\hline $\begin{array}{l}\text { Number of } \\
\text { section }\end{array}$ & Name & $\begin{array}{l}\text { Soil } \\
\text { type } \\
\text { (left) }\end{array}$ & $\begin{array}{l}\text { Soil } \\
\text { type } \\
\text { (right) }\end{array}$ & $\begin{array}{l}\text { Vegetation type } \\
\text { (left) }\end{array}$ & $\begin{array}{l}\text { Vegetation type } \\
\text { (right) }\end{array}$ \\
\hline 1 & 213 Bridge & Sand & Silt & Bare ground & Corn \\
2 & 312 Bridge & Silt & Silt & Corn & Grass \\
3 & Tielu Bridge & Silt & Silt & Corn & Grass and corn \\
4 & Pingchuan Bridge & Silt & Silt & Grass and corn & Grass and corn \\
5 & Gaotai Bridge & Sand & Sand & Grass & Corn \\
\hline
\end{tabular}

\section{Results}

\subsection{Validation}

First, we validated our model using results from the sensitivity experiments. Both responses of the groundwater table in short-term (7 days) and long-term (160 days) simulations were displayed. The results from case (a) (the river recharging the groundwater) are plotted in Fig. 4. Figure 4a-h show the time series of the simulated groundwater table depths for each grid cell in the first sensitivity experiment $\left(h_{\mathrm{r}}\right.$ was varied and $K_{\mathrm{r}}$ was held as constant). From the figures, the groundwater table depth near the river channel is significantly reduced (the groundwater head is elevated) as the river water level increases. This is because, as Eq. (1) shows, the higher river water level induces a greater hydraulic gradient, which enhances lateral recharge to the riparian aquifer. This effect is significant in both short-term and long-term simulations indicating the essential role of river level in the controlling of riparian water table. Figure $4 \mathrm{i}-\mathrm{p}$ show the time series of the simulated groundwater table depths for each grid cell in the second experiment $\left(h_{\mathrm{r}}\right.$ was held as constant and $K_{\mathrm{r}}$ was varied). From the figures, the effect of $K_{\mathrm{r}}$ is significant over the short-term simulation (Fig. $4 \mathrm{i}-1$ ): as the $K_{\mathrm{r}}$ ranged from 3 to $24 \mathrm{~m} \mathrm{day}^{-1}$, the time spent by the nearest grid (to river) to get the equilibrium state is shortened from 2 to 0.5 days. However, after long-term simulation (Fig. $4 \mathrm{~m}-\mathrm{p}$ ), the groundwater table depths are similar for all values of $K_{\mathrm{r}}$, indicating that the equilibrium state of the groundwater table along the river channel is not very sensitive to $K_{\mathrm{r}}$ compared with $h_{\mathrm{r}}$. This is because riverbed water conductivity $K_{\mathrm{r}}$ only connects the river and the nearest model grid to the river, while the rest of grids (not next to river) are not directly influenced by $K_{\mathrm{r}}$ and more affected by the lateral hydraulic conductivity $K$ of the riverbank soil (in Eq. 9). The results from case (b) (the groundwater recharging the river) were plotted in Fig. 5. The conclusions from Fig. 5 are similar to those of Fig. 4: river level matters for both short-term and long-term simulations in the controlling of the riparian water table, while the riverbed water conductivity is more important in the controlling of short-term water table variation than the controlling of long-term water table equilibrium. Figures 4 and 5 jointly validated that our model could reasonably reproduce both the processes of the river recharging the groundwater and the groundwater recharging the river.

Next, we tested our results from the realistic simulation (TEST) using observed data. First, we used observation data from the eddy covariance (EC) and automatic weather station (AWS) system of the Bajitan Gobi Desert station (Liu et al., 2011; Li et al., 2013), a part of hydrometeorological observation network operated by HiWATER, to validate our simulation. The Bajitan Gobi Desert station is located at $100.3042^{\circ}$ E, $38.9150^{\circ} \mathrm{N}$ (displayed in Fig. 3) at an elevation of $1562 \mathrm{~m}$. The station is on the northwest riverbank of the first section (213 Bridge) in our simulation at a distance of approximately $2800 \mathrm{~m}$ from the channel. The station contains a $10 \mathrm{~m}$ flux tower equipped with a series of EC instruments for flux measurements, and meteorological instruments for regular weather measurements as well as soil temperature and moisture. The underlying surface of this site is Gobi Desert soil with scarce grass. There are few human activities nearby, which benefitted our validation because anthropogenic effects are not considered in the simulation. Figure 6 shows the daily variations in the observations of surface soil temperature, surface soil moisture, sensible heat flux, and latent heat flux at the Bajitan Gobi station against the corresponding simulated values from the CTL and TEST runs. The initial observation times of the EC and AWS system were, respectively, 14 August 2012 and 19 September 2012, and there was a successive period near June 2013 with missing measurements for both sensible and latent heat flux. Figure $6 \mathrm{a}$ and $\mathrm{b}$ show that our model can correctly adjust the surface temperature throughout the year but yields surface soil moisture predictions that have a significant positive bias in spring and winter. Despite this, TEST can generally capture the peak value of soil moisture induced by rain events. Figure $6 \mathrm{c}$ shows that our model is credible for sensible heat flux simulation, albeit with underestimation of this parameter in winter. Figure $6 \mathrm{~d}$ shows that TEST also simulates the latent head flux well in the rainy season, but gives a negative bias in the arid season. Compared with CTL, simulated results of the sensible and latent heat fluxes from TEST are closer to observations, while the results of surface soil temperature and moisture are not distinguished between CTL and TEST. Overall, the TEST simulation demonstrated a reason- 
able ability of CLM_RIV to reproduce the observations of important parameters, especially in the wet season when the ecohydrological effects of stream-aquifer water interaction are dominant.

Next, we tested the ability of our model to simulate the groundwater table, which is a key factor in ecological and hydrological effects. We compared the results from both the TEST and CTL simulations with the groundwater head elevation and the groundwater table depth data from observation wells distributed over the middle reaches of the Heihe River basin (Zhou et al., 2011). There were 46 wells within our simulation domain of the five sections. Figure 7 a shows the annual values of our simulated groundwater head elevation from both TEST and CTL runs against the observed groundwater heads at the 46 wells. As shown, if the streamaquifer water transfer is not accounted (as in the CTL run), there is a significant underestimation of the water head at nearly all sites. When river-groundwater exchange is considered (as in the TEST simulation), the negative biases are much more reduced because the water transfer raises the water table, and the modeled groundwater levels are very close to the observations for most wells. However, there are still a few meters of deviation between TEST simulated levels and observed levels. The conclusions above were also shown, more apparently, by the comparison of the groundwater table depth in Fig. 7b. Figure 7c shows the spatial distribution of the groundwater table depth from observation, TEST, and CTL over the Gaotai Bridge, along which the most number of wells were deployed. We can also see that the systematic errors of simulated groundwater tables were obviously reduced along the whole riverbank after the stream-aquifer water interaction was taken into account, though a few meters of deviation still existed. The deviation of these results may come from the chosen saturated hydraulic conductivity values, which in this study were chosen a priori and as such not optimized in any kind of manner.

Next, we checked the model's ability to simulate spatial variability by comparing simulated ground temperature from the CTL and TEST runs with high-resolution remote sensing data from the Advanced Spaceborne Thermal Emission and Reflection Radiometer (ASTER) launched by the United States National Aeronautics and Space Administration (Tachikawa et al., 2011). The ASTER data had been post-processed for the Heihe River basin by Li et al. (2014). Ground temperature measurements at $90 \mathrm{~m}$ resolution were available for five satellite transit events during the summer of 2012. We used relative temperature of the nearest grid to the stream to emphasize spatial variability. The northwest (left) riverbank of the 213 Bridge station was chosen for our comparison because human activities could be neglected there. Figure 8 shows that in four of the five events TEST successfully simulated the increase in ground temperature as distance from the channel increased, while the CTL could not reproduce this spatial variability. However, in the fourth event, the spatial variability predicted by the TEST simula- tion is much lower than that indicated by ASTER data. This may be caused by the fact that ASTER data are not processed with a cloud mask, which causes overestimation of the cooling effects of streamflow on a cloudy day (Li et al., 2014).

\subsection{Ecohydrological effects of stream-aquifer water interaction}

\subsubsection{Intra-annual responses to river water level}

First, we examined the intra-annual responses of ecohydrological characteristics to river water level variations. Figure 9 shows the intra-annual variations (at $1800 \mathrm{~s}$ intervals) of water heads and water table depth at 30, 90, 210 and $450 \mathrm{~m}$ from the channel on the left riverbanks of streams at the five stations, as well as the observed river water levels. As Fig. 9a-e show, the $30 \mathrm{~m}$ water heads are tightly connected with river levels and have slightly lower elevations and change frequencies. The $90 \mathrm{~m}$ water heads also follow the river level fluctuations but with some time lags, and the elevations are much lower than the river levels and more resistant to change. At 210 and $450 \mathrm{~m}$ from the stream, there is no discernable relation between water table heads and river water levels, and the former are very stable within the year. The performances of simulated water table depth in Fig. $9 f-j$ are similar to the water head elevations. Figure 9 shows the region that can receive the intra-annual signal of river level changes by stream-aquifer interaction is restricted within a limited distance from the channel, and the response to this signal is stronger closer to the river than farther away. The time correlation coefficients between the groundwater tables across the left riverbanks and the river levels of the five sections are plotted in Fig. 10. Considering the time lags of the signal transduction, we used the maximum value of crosscorrelation coefficients with time lags from 0 to 3 months (at $1800 \mathrm{~s}$ intervals). The standard line where the correlation coefficient passes the $95 \%$ confidence level of the Student's $t$ test is also plotted in Fig. 10. As shown in Fig. 10, the correlation coefficients between the groundwater tables and river levels are more than 0.9 for locations very near to streams, but decrease rapidly as distances from channels increase. The left riverbanks of the 213 Bridge and Pingchuan Bridge stations are least impacted by intra-annual river fluctuations; only at locations within $200 \mathrm{~m}$ from streams at these stations do correlation coefficients pass the Student's $t$ test. The most affected riverbank is located at Tielu Bridge station, where intra-annual river level fluctuations influence the water table elevations as far as $450 \mathrm{~m}$ from the stream. Nonetheless, the area impacted by intra-annual river water level fluctuations (i.e., a zone within $450 \mathrm{~m}$ of a stream) is much smaller than that impacted by stream-aquifer exchange (i.e., a zone extending to $1800 \mathrm{~m}$ from a stream, see Sect. 4.2.2.).

We then examined the responses of other ecohydrological characteristics to intra-annual river water level changes. To highlight the outcomes, we show the simulation results at 

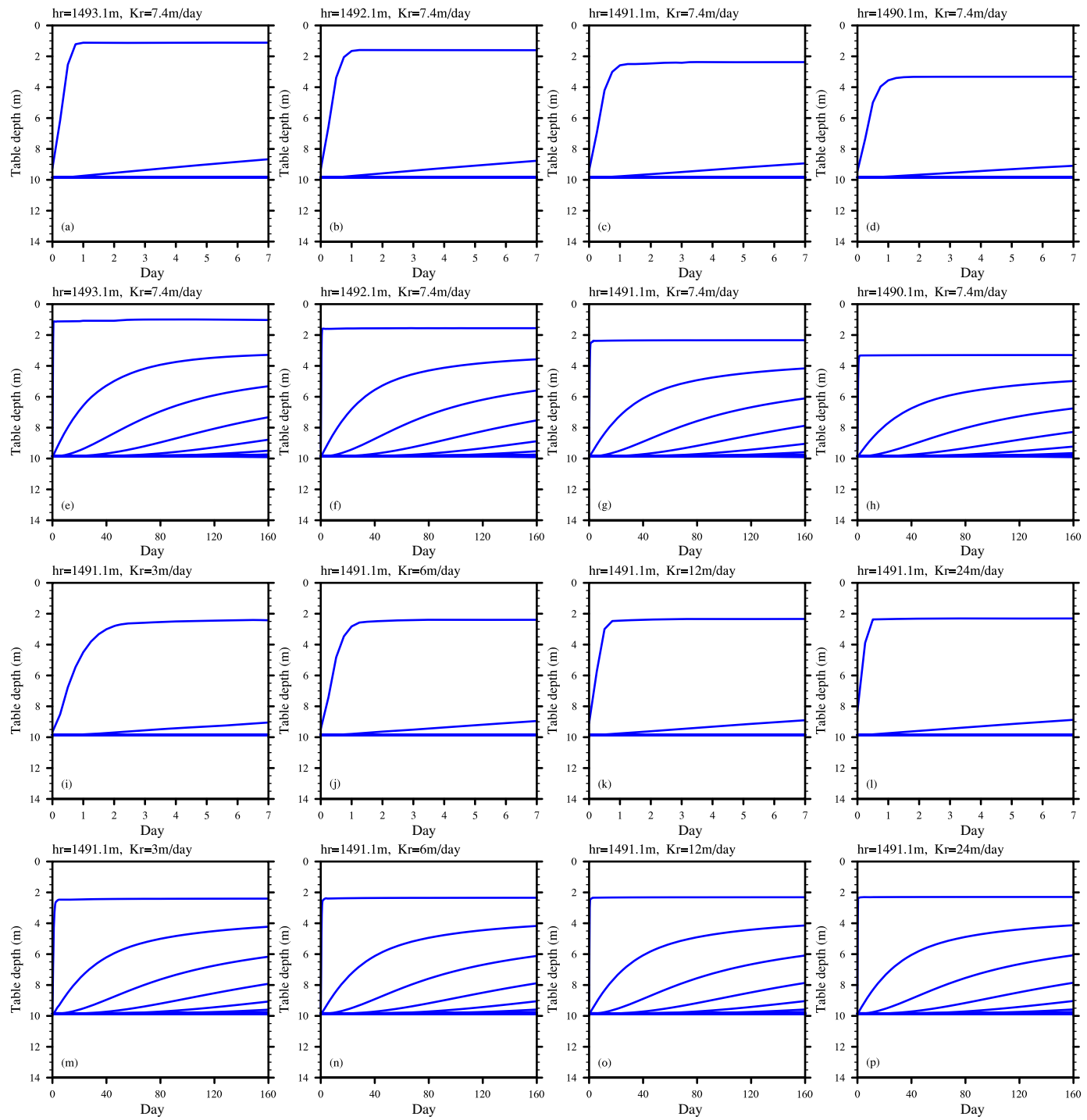

Figure 4. Short-term $(\mathbf{a}-\mathbf{d}, \mathbf{i}-\mathbf{l})$ and long-term $(\mathbf{e}-\mathbf{h}, \mathbf{m}-\mathbf{p})$ responses of the riparian groundwater table to the river water level $h_{\mathrm{r}}$ and riverbed hydraulic conductivity $K_{\mathrm{r}}$ in the case of the river recharging the groundwater. Time series of the simulated groundwater table depths for each grid cell in the first sensitivity experiment $(\mathbf{a}-\mathbf{h})$. Time series for the second sensitivity experiment (i-p).

two rather contrasting stations, Tielu Bridge and 213 Bridge; these stations demonstrated the longest and shortest propagation distances, respectively, for river level fluctuation (Fig. 10). We plot the area-averaged data within a $300 \mathrm{~m}$ range from both sides of the streams.

Figure 11 shows the time series of selected daily ecological and hydrological variables predicted by TEST and CTL simulations, as well as the river levels and precipitation within the simulation period for the Tielu Bridge section. Figures 11c and 10d show that the effects of stream-aquifer interaction on surface soil water and surface ice, respectively, are dominant in spring, autumn, and winter. As expected, the effects on surface soil ice are especially noticeable in winter, with values predicted by the TEST simulation nearly 5 times those predicted by CTL. The relative lack of influence of the high river water level of summer (Fig. 11a) on soil water seems contradictory, but can be explained by the precipitation variation shown in Fig. 11b; in summer, surface soil is wetted most by precipitation and stream water contributes relatively less to this effect, while in other seasons the stream water can significantly affect the surface soil water (and ice) because rain events are sparse. These conclusions can be checked in Fig. 11e, which shows that the effects of stream-aquifer interaction are perennially apparent on deep soil water that is much less affected by rain. Figure $11 \mathrm{~g}$ shows that ground temperature is cooled by stream water in spring and summer and warmed in winter, though the amplitudes of these changes are slight compared with seasonal temperature variation. The higher specific heat capacity induced by wetter soil makes soil temperatures more 

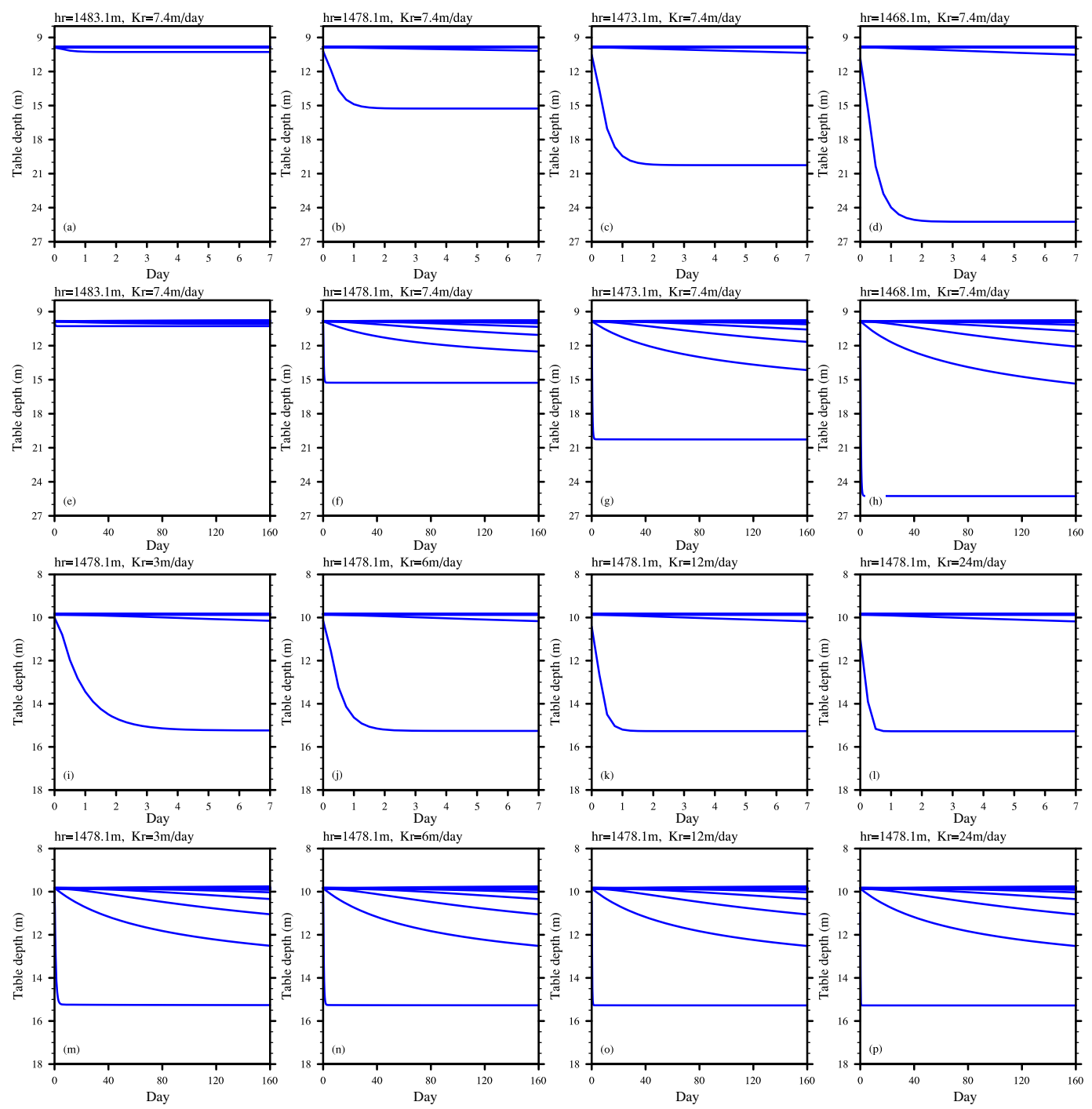

Figure 5. Short-term (a-d, i-l) and long-term $(\mathbf{e}-\mathbf{h}, \mathbf{m}-\mathbf{p})$ responses of the riparian groundwater table to the river water level $h_{\mathrm{r}}$ and riverbed hydraulic conductivity $K_{\mathrm{r}}$ in the case of the groundwater recharging the river. Time series of the simulated groundwater table depths for each grid cell in the first sensitivity experiment $(\mathbf{a}-\mathbf{h})$. Time series for the second sensitivity experiment (i-p).

resistant to the influence of air temperature change than when the soil is dry.

Intra-annual impacts on GPP and ecosystem respiration (RE) are shown in Fig. 11h and i, respectively. Generally, GPP and RE are both strengthened by stream-aquifer water interaction all year except in winter, and the increased GPP (approximately $0.03 \mathrm{mg} \mathrm{C} \mathrm{m}^{-2} \mathrm{~s}^{-1}$ in the growing season) is higher than RE (approximately $0.02 \mathrm{mg} \mathrm{C} \mathrm{m}^{-2} \mathrm{~s}^{-1}$ ) most of the time. These differences enhance the NEE by approximately $0.01 \mathrm{mg} \mathrm{C} \mathrm{m}^{-2} \mathrm{~s}^{-1}$ in the growing season, which means that riparian plants fix more $\mathrm{CO}_{2}$ from May to September than at other times of the year (as Fig. 11j shows). However, there is a time period from March to April when $\mathrm{RE}$ is enhanced by stream water supplement, while GPP is unaffected. This time lag causes the riparian vegetation to act as a strong carbon source in this period (Fig. 11j) instead of as a sink at other times of the year.

The incremental leaf area index (LAI) and evapotranspiration by water recharge from the river are shown in Fig. 11k and 1 , respectively. The LAI is much increased from April to December relative to other times and the stream water supplement can even advance the beginning and delay the ending of the growing season for 1-2 months (Fig. 11k). Predictions from the TEST simulation indicate that LAI is closer to 0 near September 2012, corresponding to the dry river water condition around this time (Fig. 11a); this result underlines the high sensitivity of riparian plant growth to the streamaquifer water interaction. Figure 111 shows that evapotranspiration variability within the year is also highly related to 

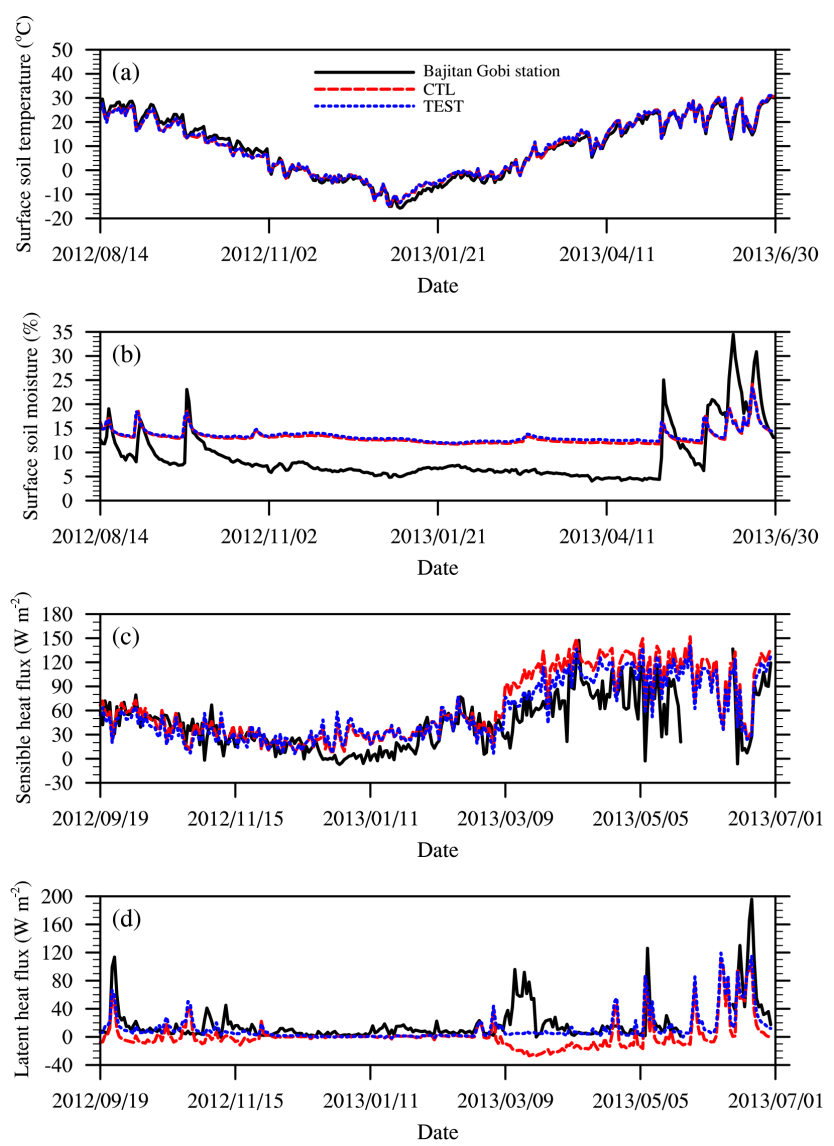

Figure 6. Time series of the observations from the eddy covariance and automatic weather station systems and results from the CTL and TEST simulations at Bajitan Gobi station for (a) surface soil temperature, (b) surface soil moisture, (c) sensible heat flux, and (d) latent heat flux.

the fluctuation in river level, reemphasizing the key functions of environmental flows for an ecological system.

Figure 12 shows the time series of selected daily ecological and hydrological variables predicted by TEST and CTL simulations, as well as the river levels and precipitation within the simulation period for the 213 Bridge section. The conclusions based on TEST and CTL simulations for Tielu Bridge are generally applicable to the section at 213 Bridge as shown in Fig. 12, which means that the intraannual responses of ecohydrological elements to river water level changes are similar at a wide range of sections in this arid region. However, due to the propagation distance of river level fluctuation at the 213 Bridge section being much shorter than at Tielu Bridge (Fig. 10), the strength of these hydrological and ecological responses is significantly weaker at 213 Bridge than at Tielu Bridge. The differences can be observed by comparing Figs. 11 and 12 .
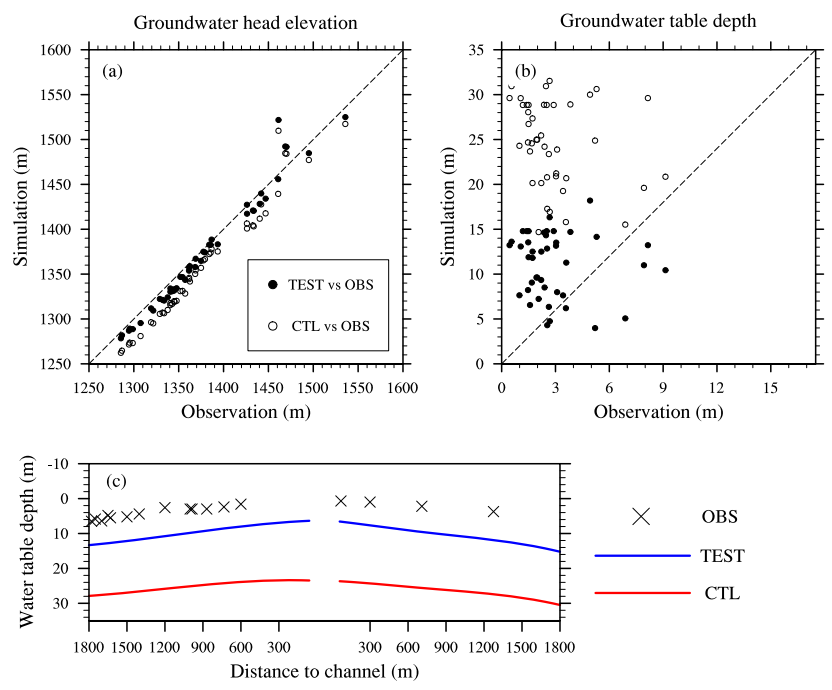

Figure 7. (a) Annual groundwater head elevation, (b) groundwater table depth predicted by TEST and CTL simulations against observed climatology water head data from 46 observation wells and (c) spatial distribution of the groundwater table depth from observation, TEST, and CTL over the Gaotai Bridge.

\subsubsection{Annual averaged effects of stream-aquifer water interaction along riverbanks}

After studying the intra-annual responses of the riparian ecohydrological system to river water fluctuation, we examined the annual averaged effects of stream-aquifer water interaction on riparian ecohydrological elements along riverbanks.

Figure 13 shows the differences of annual water heads between predictions from TEST and CTL simulations and the terrain elevations along the five sections. All sections show stronger effects of elevated water tables closer to the stream than farther away. The water exchange from stream to aquifer can increase the water head at the grid nearest to the stream ( $30 \mathrm{~m}$ from the channel) by $13-22 \mathrm{~m}$. Furthermore, all cross sections show water table elevations increased by more than $8 \mathrm{~m}$ even at sites nearly $2 \mathrm{~km}$ from channels. When averaged for the area within $1800 \mathrm{~m}$ from either side of the river channel, the groundwater tables rose by approximately $10-20 \mathrm{~m}$ at the five sections. These results show that the effects of stream-aquifer water interaction on annual averaged groundwater levels can spread very far by groundwater lateral flow. Thus, groundwater studies must consider the impacts of water exchange between a riverbank and river, a point also stressed by other researchers (Miguez-Macho et al., 2007; Chen et al., 2010; Di et al., 2011). As shown in Fig. 13, the relationship between the curve shape of elevation and the water head along the riverbank can be generally figured out: when the terrain is relatively flat, an apparent curvature of the water head occurs, such as on the left side of 213 Bridge and Pingchuan Bridge, and on the right side of Tielu Bridge; when the curvature of the terrain is obvi- 

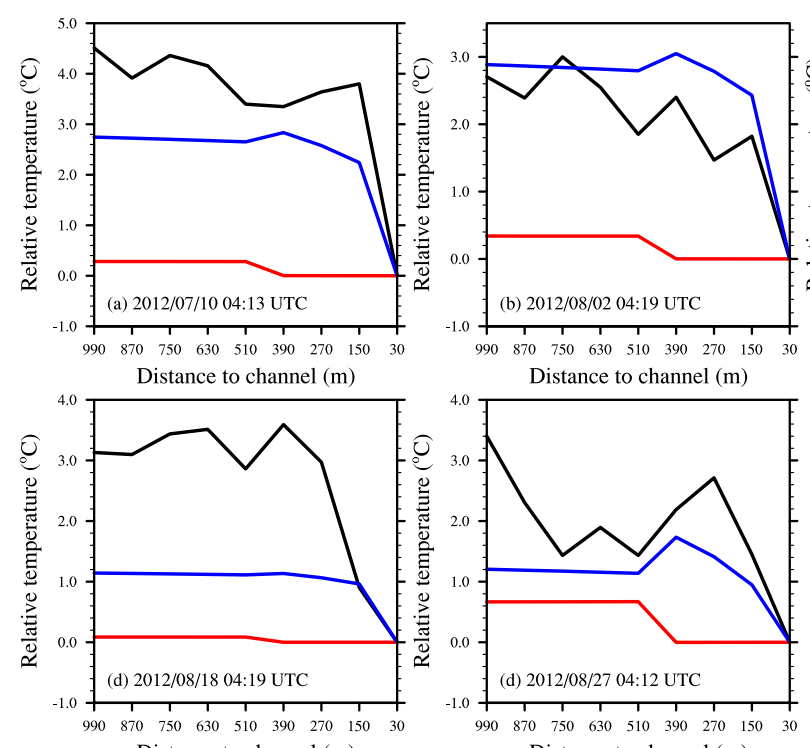

Distance to channel (m)

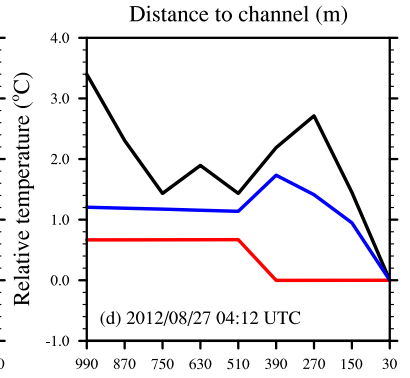

Distance to channel (m)

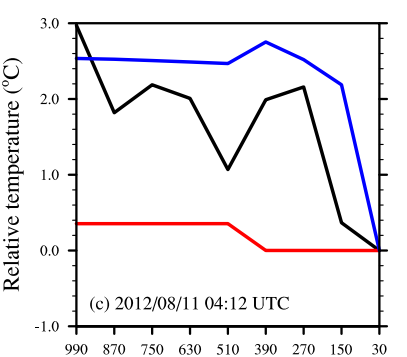

Distance to channel (m)

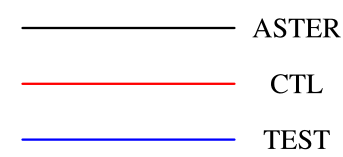

Figure 8. Relative ground temperature across the left riverbank of the 213 Bridge station from the CTL and TEST simulations and corresponding remote sensing data from five ASTER satellite transit events of (a) 10 July 2012 at 04:13 UTC, (b) 2 August 2012 at 04:19 UTC, (c) 11 August 2012 at 04:12 UTC, (d) 18 August 2012 at 04:19 UTC, and (e) 27 August 2012 at 04:12 UTC.

ous, the curve of the water head is relatively flat, such as on the left side of 312 Bridge and Tielu Bridge, and on the right side of Pingchuan Bridge. However, the curve shape of the water head is determined by multiple factors such as the groundwater recharge, soil type, and aquifer thickness. The topography is the only (maybe the most) influential one of these factors. This topographic factor also explained why the effects of river water conveyance are not symmetrical over the left and right sides.

Figure 14 shows the differences of summer and winter soil moisture (both liquid water and ice are included) predicted by TEST and CTL simulations along the five sections. Predictions at two depths $(2$ and $100 \mathrm{~cm}$ ) are chosen to represent the surface and deep soil layers, respectively. Figure 14ae show that in summer, the deep soil moisture is increased by stream water from 0.08 to $0.16 \mathrm{~m}^{3} \mathrm{~m}^{-3}$ at the grid closest to the channel, and that this wetting effect is weaker as the distance from the river increases. Averaged for the region within $1 \mathrm{~km}$ from the stream, the deep soil is wetted by river water by approximately $0.05 \mathrm{~m}^{3} \mathrm{~m}^{-3}$ (a $30 \%$ increase) at the riverbank. However, the surface soil moisture is nearly unaffected by stream-aquifer interaction because in summer, surface soil moisture is dominated by precipitation and stream water contributes little to the soil moisture changes. This conclusion is verified in Fig. $14 \mathrm{f}-\mathrm{j}$. In winter, when rain events are sparse, the wetting effects of stream-aquifer interaction on surface soil moisture are apparent at all sections, though the magnitudes are small (only approximately $0.02 \mathrm{~m}^{3} \mathrm{~m}^{-3}$, a $10 \%$ increase) compared with the wetting effects on deep soil. Wetter soil supplies more water for riparian plant growth and subsistence than dry soil, especially in the growing sea- son in an arid region, which stresses the necessity of streamaquifer water interaction in supporting the riparian environment.

The annual averaged ecological effects of stream-aquifer water interaction were also evaluated. Figure 15 shows differences in predicted GPP, RE (both autotrophic and heterotrophic respiration are included), and NEE resulting from TEST and CTL simulations for the summer period. Because there is no vegetation on the northwest (left) side of the 213 Bridge station, all the values are 0 (Fig. 15a). Figure 15 shows that GPP and RE increased as the distance to the channel decreased, while NEE increased (with the ecosystem tending to be a carbon sink) by 0.002 $0.005 \mathrm{mg} \mathrm{C} \mathrm{m}^{-2} \mathrm{~s}^{-1}(100-300 \%)$. The impacts are evident within a range of approximately $1 \mathrm{~km}$. The strongest effects appeared at Tielu Bridge station with increases of more than $0.05 \mathrm{mg} \mathrm{C} \mathrm{m}^{-2} \mathrm{~s}^{-1}$ for GPP and $0.04 \mathrm{mg} \mathrm{C} \mathrm{m}^{-2} \mathrm{~s}^{-1}$ for RE, and a decrease of about $0.01 \mathrm{mg} \mathrm{C} \mathrm{m}^{-2} \mathrm{~s}^{-1}$ for NEE at the grid nearest to the stream. The influences of stream-aquifer interaction on GPP are stronger than they are on RE at all sections; this difference explains why the stream effects on NEE are negative (carbon sink) and means that riparian vegetation can absorb more $\mathrm{CO}_{2}$ and grow better when it is closer to the river. These results highlight the maintenance function of stream-aquifer water interaction for a riparian ecosystem, especially in an arid region.

The simulated effects of stream-aquifer interaction on LAI and canopy transpiration (canopy evaporation is also included) in the summer period are provided in Fig. 16. Differences in LAI and transpiration predicted by the TEST and CTL simulations show similar spatial patterns at all sec- 

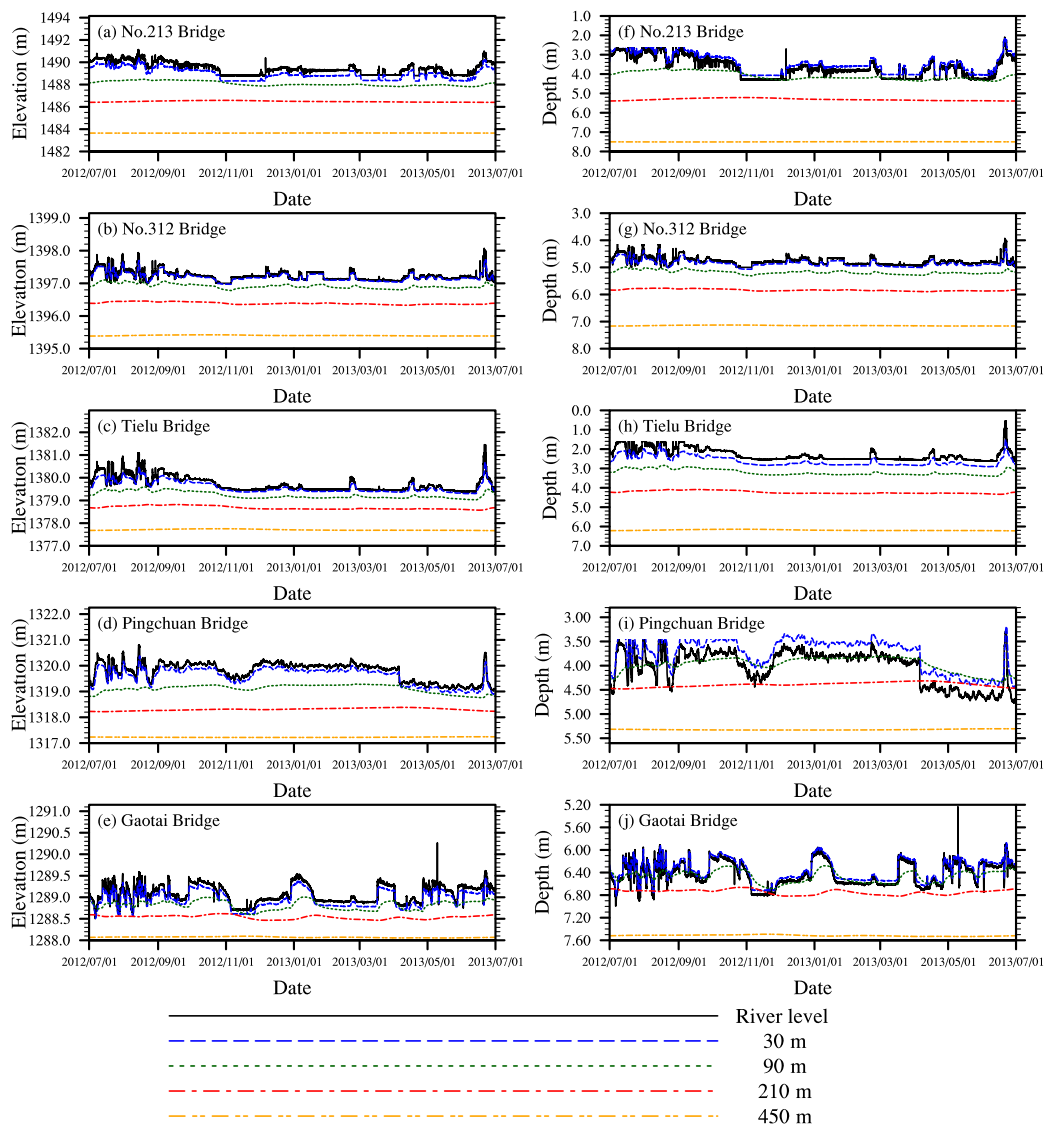

Figure 9. Time series of simulated (a-e) water head elevations and (f-j) water table depths at 30, 90, 210, and 450 $\mathrm{m}$ from streams and the observed river water levels at the five left riverbanks of stations at (a, f) 213 Bridge, (b, g) 312 Bridge, (c, h) Tielu Bridge, (d, i) Pingchuan Bridge, and (e, j) Gaotai Bridge.

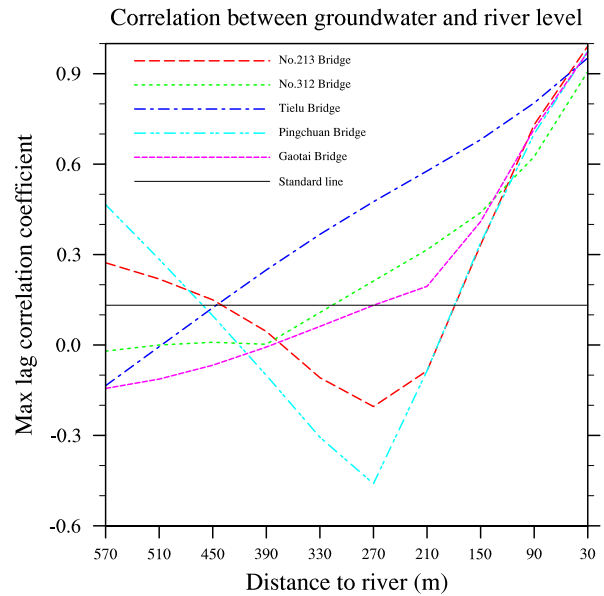

Figure 10. Maximum lag correlation coefficients between simulated groundwater tables across the left riverbanks and the river water levels at the five stations, and the standard line representing the value of correlation coefficient passing the Student's $t$ test with a confidence level of $95 \%$. tions; in close proximity to the river, LAI and transpiration are increased by supplemental water from the stream. The impacted areas are also within approximately $1 \mathrm{~km}$ from the channel for most riverbanks. Averaged over the affected area, the transpiration is enhanced by $0.2-1.0 \mathrm{~mm} \mathrm{day}^{-1}$ (about $100-200 \%$ ) and LAI is increased by $0.2-1$ in summer. The strongest affected section is Tielu Bridge where the LAI and canopy transpiration increased by approximately 5.0 and $4 \mathrm{~mm} \mathrm{day}^{-1}$, respectively, at the closest grid to the stream (Fig. 16c); riverbanks of other sections are less impacted. The similar spatial distributions of LAI and transpiration across riverbanks mean that in this arid region, transpiration along the river is mainly controlled by LAI, which will benefit from stream water lateral infiltration. This finding again stresses the essential influence of stream-aquifer water interaction in riparian hydrologic and carbon cycles, as well as in maintaining environmental integrity.

Lastly, we show the effects of stream-groundwater exchange on vertical energy and water fluxes along a river. Figure 17 shows the differences in sensible heat $(\mathrm{SH})$ and latent heat (LH) fluxes predicted by the TEST and CTL simulations for summer and winter. Figure 17a-e show that the effects 

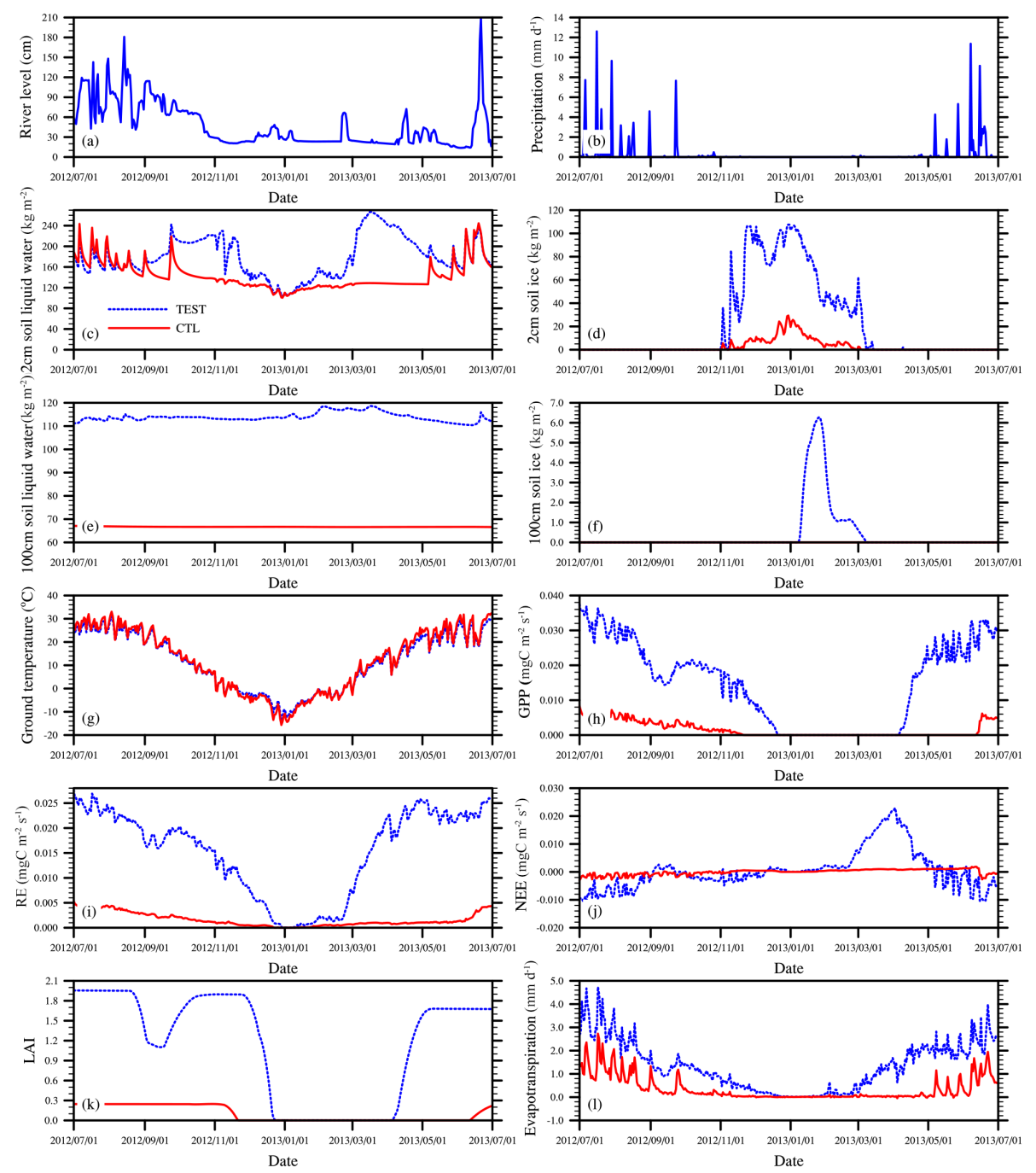

Figure 11. Time series of area-averaged daily (a) observed river level and (b) observed precipitation, as well as (c) $2 \mathrm{~cm}$ soil liquid water, (d) $2 \mathrm{~cm}$ soil ice, (e) $100 \mathrm{~cm}$ soil liquid water, (f) $100 \mathrm{~cm}$ soil ice, (g) ground temperature, (h) gross primary productivity, (i) respiration efficiency, (j) net ecosystem exchange, (k) leaf area index, and (l) evapotranspiration predicted by TEST and CTL simulations within $300 \mathrm{~m}$ of both sides of the stream at the Tielu Bridge station.

on SH and LH in summer display opposite trends along the riverbanks: LH becomes stronger closer to the stream while $\mathrm{SH}$ becomes weaker. The stronger LH is due to the enhanced evapotranspiration along the river (Fig. 16), which also induces weaker SH. However, the SH and LH display the same trends in winter. Figure $17 \mathrm{f}-\mathrm{j}$ show that both $\mathrm{SH}$ and $\mathrm{LH}$ exhibit small positive changes closer to riverbanks, though the magnitudes are much smaller than they are in summer; this may be induced by the lower river water level in winter (Fig. 9). Because SH and LH are key factors influencing the atmosphere above a plant canopy, local weather and climate would also be modified by the effects of stream-aquifer water interaction; this suggests that when studying local climate in areas that include streams, the effects of surface water should not be ignored.

\section{Conclusions and discussion}

In this study, we combined a scheme of stream-aquifer water interaction with the land model CLM4.5 to investigate the ecohydrological effects of stream-aquifer water interaction over riverbanks. After sensitivity tests for selected parameters demonstrated the reliability of the combined model (CLM_RIV), the model was used to make two simulations to detect the effects of stream-aquifer water interaction on ecological and hydrological processes on riparian banks at five different locations. One simulation was "forced" using observed river water levels. The other "control" simulation did not take stream-aquifer water exchange into consideration. Both simulations covered a period from July 2012 to June 2013. Comparisons of simulation outputs and observations from EC and AWS systems, water wells, and remote 

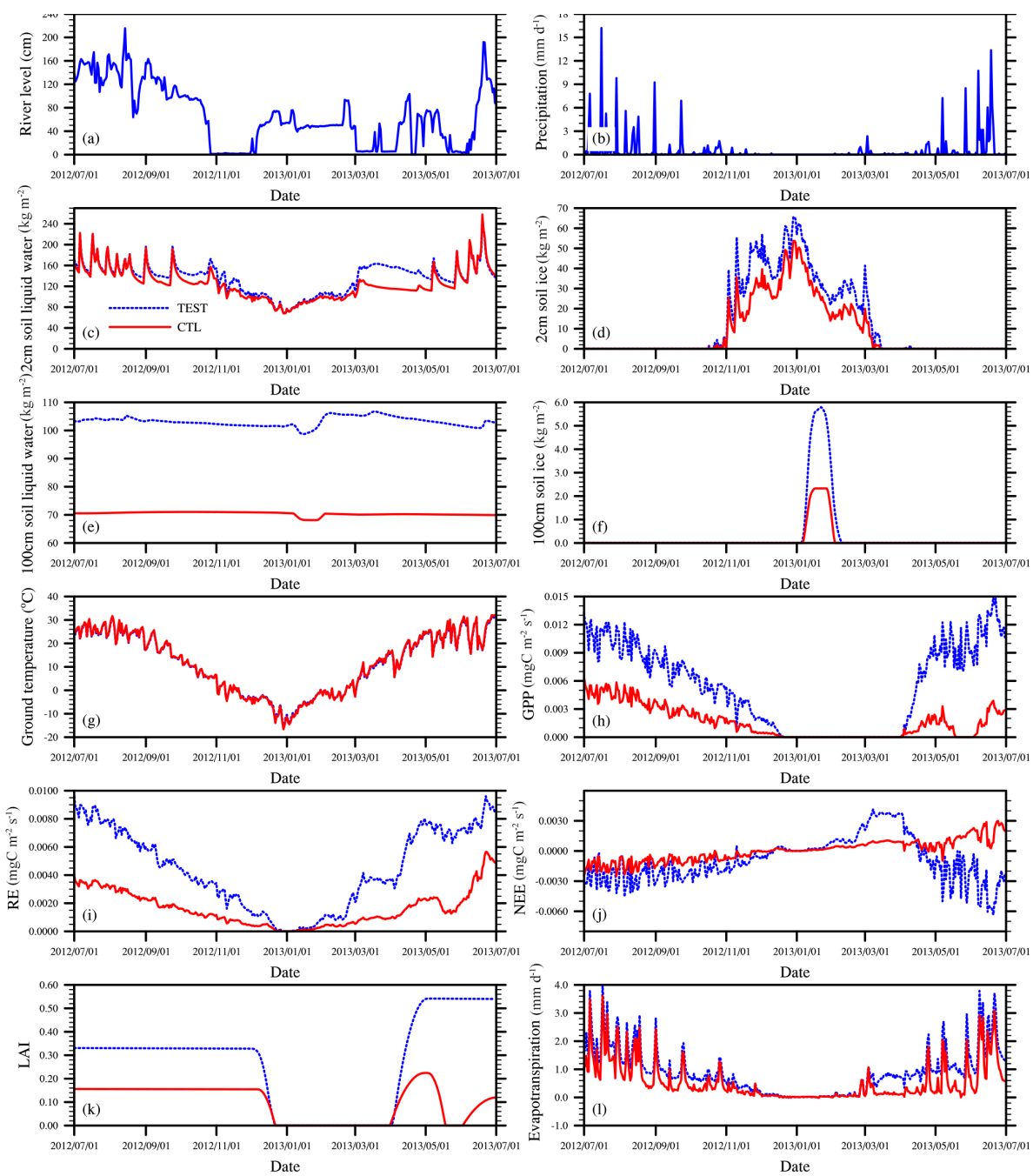

Figure 12. Time series of area-averaged daily (a) observed river level and (b) observed precipitation, as well as (c) $2 \mathrm{~cm}$ soil liquid water, (d) $2 \mathrm{~cm}$ soil ice, (e) $100 \mathrm{~cm}$ soil liquid water, (f) $100 \mathrm{~cm}$ soil ice, (g) ground temperature, (h) gross primary productivity, (i) respiration efficiency, (j) net ecosystem exchange, (k) leaf area index, and (l) evapotranspiration predicted by TEST and CTL simulations within $300 \mathrm{~m}$ of both sides of the stream at the 213 Bridge station.

sensing data demonstrated that CLM_RIV shows considerable ability to reproduce the natural conditions along riverbanks.

The main conclusions of this study are as follows:

1. A riparian groundwater table responds to the intraannual variation in river water level, but the response areas are limited to within $200-450 \mathrm{~m}$ from the stream channel. The correlation coefficient between the groundwater table and river level can reach 0.9 at the nearest model grid to the river, but rapidly decreases as the distance from the river increases. Surface soil liquid water in the rainy season is less impacted by river level variation than is deep soil water, which follows the river level fluctuation all year.
2. Over a typical riverbank section (Tielu Bridge), averaged GPP and respiration of riparian vegetation within $300 \mathrm{~m}$ from the stream increased by approximately 0.03 and $0.02 \mathrm{mg} \mathrm{C} \mathrm{m}^{-2} \mathrm{~s}^{-1}$, respectively, in the growing season due to increased soil water, resulting in enhanced NEE of approximately $0.01 \mathrm{mg} \mathrm{C} \mathrm{m}^{-2} \mathrm{~s}^{-1}$. Evapotranspiration in this zone also increased (by approximately $3 \mathrm{~mm} \mathrm{day}^{-1}$ ). Furthermore, the growing season of riparian vegetation is also extended by $2-$ 3 months due to the sustaining water recharge from the stream, and even a short-term decline in river level can negatively impact LAI near the stream during the growing season.

3. All impacted ecological and hydrological characteristics are restricted to an area within approximately $1 \mathrm{~km}$ 

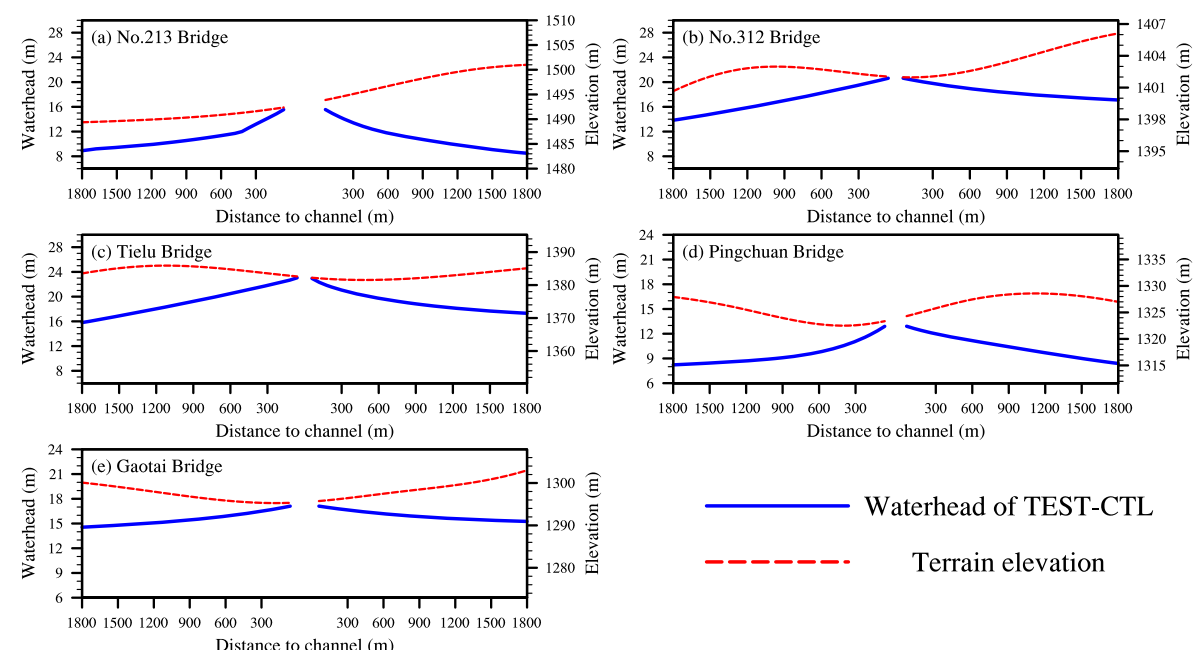

Distance to channel (m)

Figure 13. Differences between annual water heads predicted by TEST and CTL simulations and terrain elevations along the five sections at (a) 213 Bridge, (b) 312 Bridge, (c) Tielu Bridge, (d) Pingchuan Bridge, and (e) Gaotai Bridge. The discontinuous parts of the curves represent the river areas.
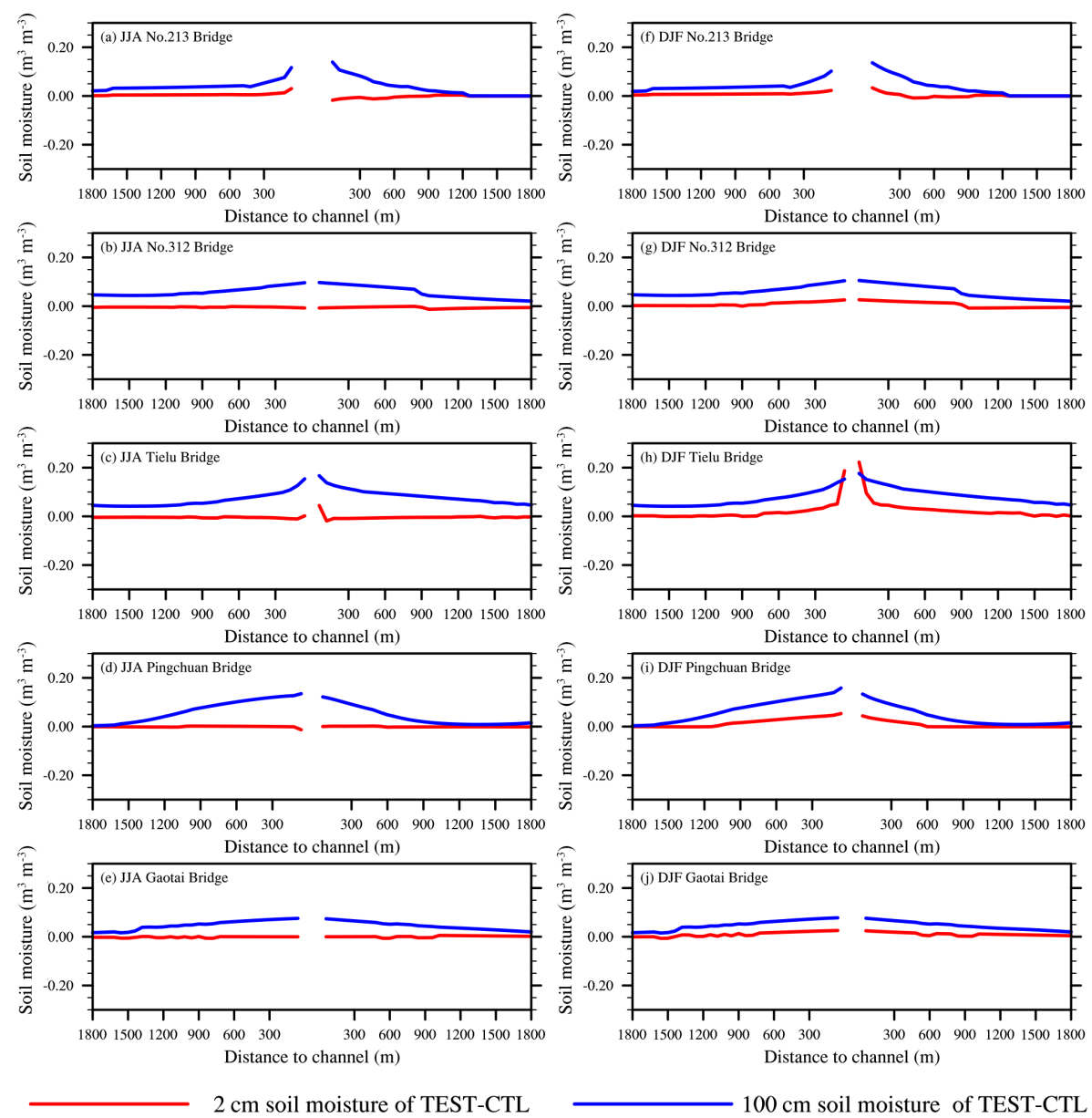

Figure 14. Differences of (a-e) summer and (f-j) winter soil moisture (both liquid water and ice are included) predicted at depths of 2 and $100 \mathrm{~cm}$ by TEST and CTL simulations along the five sections at (a, f) 213 Bridge, (b, g) 312 Bridge, (c, h) Tielu Bridge, (d, i) Pingchuan Bridge, and (e, j) Gaotai Bridge. The discontinuous parts of the curves represent the river areas. 

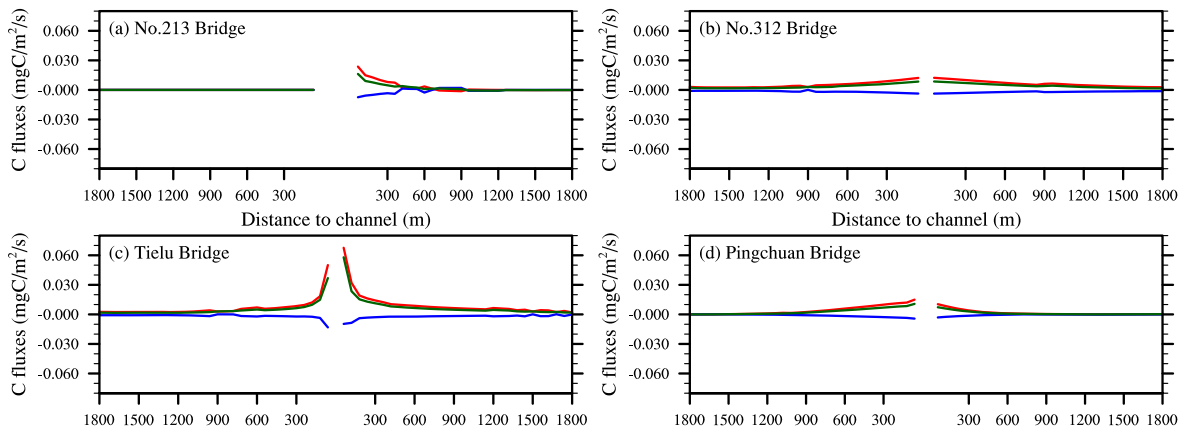

Distance to channel (m)
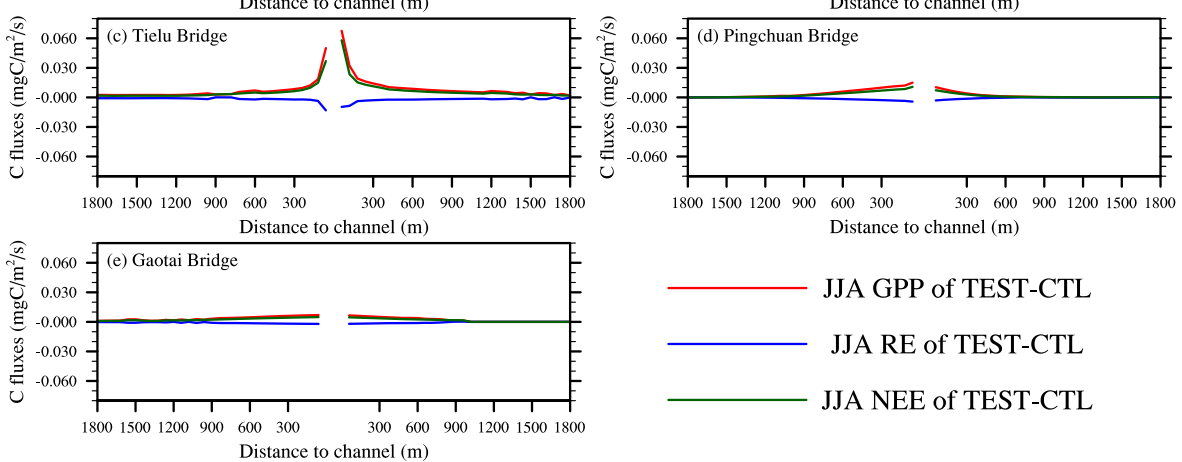

Distance to channel (m)

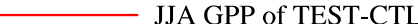

JJA RE of TEST-CTL

JJA NEE of TEST-CTL

Figure 15. Differences between gross primary productivity, respiration efficiency and net ecosystem exchange predicted by TEST and CTL simulations during summer along the five sections at (a) 213 Bridge, (b) 312 Bridge, (c) Tielu Bridge, (d) Pingchuan Bridge, and (e) Gaotai Bridge. The discontinuous parts of the curves represent the river areas.
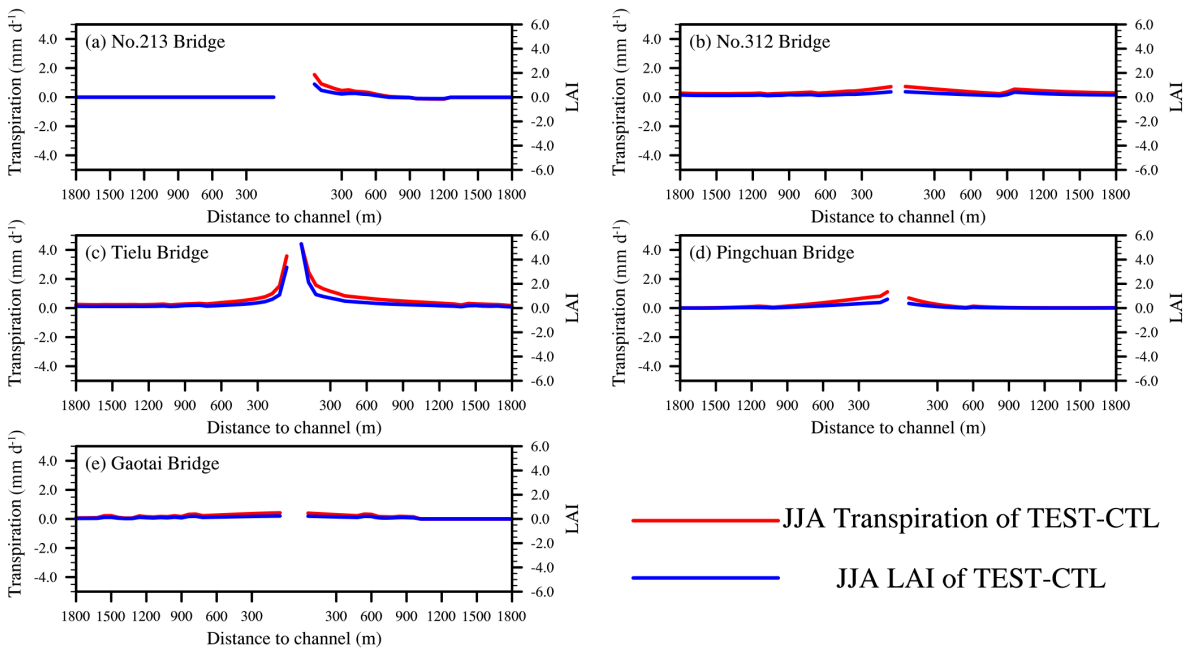

Figure 16. Differences between canopy transpiration and leaf area index predicted by TEST and CTL simulations during summer along the five sections at (a) 213 Bridge, (b) 312 Bridge, (c) Tielu Bridge, (d) Pingchuan Bridge, and (e) Gaotai Bridge. The discontinuous parts of the curves represent the river areas.

from the channel, and the effects become stronger as distance to the river decreases. These conclusions highlight the functions of stream-aquifer water interaction on sustaining and controlling the riparian ecological system, and indicate the potential benefits of water regulation, such as through artificial stream water conveyance, to maintain stream flow.

However, there are assumptions and limitations of this study that should be noted. Besides the intrinsic uncertainties of CLM and atmospheric forcing (Bonan et al., 2011, 2013; Mao et al., 2012; Wang et al., 2013), the parameters reflecting the land and river conditions in our scheme, such as $K_{j}, K_{\mathrm{r}}$ and $f$ in Eqs. (4)-(14), are highly parameterized based on some simple assumptions to facilitate data collection and computation, while the real states of geological structures and sediment-bedrock profiles are so complex that they are almost impossible to describe accurately. However, the sensitivity experiments and comparison of our results with data from multiple sources (Sect. 4.1) prove that these uncertainties do not significantly affect the simulation ability of CLM_RIV. Another restriction on our results is that human activities, such as irrigation that may take place on riverbanks, are not considered in our model. Such activities could cause our results to deviate considerably from the 



Figure 17. Differences of (a-e) sensible and $(\mathbf{f}-\mathbf{j})$ latent heat fluxes predicted by TEST and CTL simulations along the five sections at (a, f) 213 Bridge, (b, g) 312 Bridge, (c, h) Tielu Bridge, (d, i) Pingchuan Bridge, and (e, j) Gaotai Bridge. The discontinuous parts of the curves represent the river areas.

real situation. Arguably, the aim of this study was to emphasize the effects of stream-aquifer water interaction (which is a totally natural process) on riparian ecohydrological processes. Thus, ignoring anthropogenic disturbances on riverbanks (such as crop cultivation, irrigation, and water diversion), which may interfere with the natural influences we simulated, was a reasonable approach in this research.

Some future studies are also needed. To overcome the uncertainties of parameterization, more systematic experiments to test the sensitivity of model parameters should be conducted, and corresponding observations or more sophisticated estimation approaches for key parameters relating to stream-aquifer interaction are needed. Finally a land-riveratmosphere interaction model that can simulate the water and energy exchange between each component is needed for studying the more comprehensive effects of stream water flows.
Acknowledgements. This study was supported by the National Natural Science Foundation of China (grants 91125016, 41575096, and 41305066) and by the Chinese Academy of Sciences Strategic Priority Research Program under Grant XDA05110102. We would like to thank Xing Yuan, Xiangjun Tian, and Yuanyaun Wang for their assistance with this work and helpful discussion.

Edited by: Y. Chen

\section{References}

Arnold, J., Muttiah, R. S., Srinivasan, R., and Allen, P.: Regional estimation of base flow and groundwater recharge in the Upper Mississippi river basin, J. Hydrol., 227, 21-40, 2000.

Baskaran, S., Ransley, T., Brodie, R., and Baker, P.: Investigating groundwater-river interations using environmental tracers, Aust. J. Earth Sci., 56, 13-19, 2009.

Bear, J.: Dynamics of fluids in porous media, American Elsevier, New York, 361-373, 1972. 
Bonan, G. B., Lawrence, P. J., Oleson, K. W., Levis, S., Jung, M., Reichstein, M., Lawrence, D. M., and Swenson, S. C.: Improving canopy processes in the Community Land Model version 4 (CLM4) using global flux fields empirically inferred from FLUXNET data, J. Geophys. Res.-Biogeo., 116, G02014, doi:10.1029/2010JG001593, 2011.

Bonan, G. B., Hartman, M. D., Parton, W. J., and Wieder, W. R.: Evaluating litter decomposition in earth system models with long-term litterbag experiments: an example using the Community Land Model version 4 (CLM4), Global Change Biol., 19, 957-974, 2013.

Chen, F. and Xie, Z. H.: Effects of interbasin water transfer on regional climate: A case study of the Middle Route of the South-toNorth Water Transfer Project in China, J. Geophys. Res.-Atmos., 115, D11112, doi:10.1029/2009jd012611, 2010.

Chen, F. and Xie, Z. H.: Effects of crop growth and development on regional climate: a case study over East Asian monsoon area, Clim. Dynam., 38, 2291-2305, doi:10.1007/s00382-011-1125-y, 2012.

Chen, Y., Zhang, D. Q., Sun, Y. B., Liu, X. N., Wang, N. Z., and Savenije, H. H. G.: Water demand management: A case study of the Heihe River Basin in China, Phys. Chem. Earth, 30, 408-419, 2005.

Chen, Y. N., Zhang, X. L., Zhu, X. M., Li, W. H., Zhang, Y. M., Xu, H. L., Zhang, H. F., and Chen, Y. P.: Analysis on the ecological benefits of the stream water conveyance to the dried-up river of the lower reaches of Tarim River, China, Sci. China Ser. D, 47, 1053-1064, doi:10.1360/03yd0101, 2004.

Chen, Y. N., Chen, Y. P., Xu, C. C., Ye, Z. X., Li, Z. Q., Zhu, C. G., and Ma, X. D.: Effects of ecological water conveyance on groundwater dynamics and riparian vegetation in the lower reaches of Tarim River, China, Hydrol. Process., 24, 170-177, doi:10.1002/hyp.7429, 2010.

Contreras, S., Jobbagy, E. G., Villagra, P. E., Nosetto, M. D., and Puigdefabregas, J.: Remote sensing estimates of supplementary water consumption by arid ecosystems of central Argentina, J. Hydrol., 397, 10-22, doi:10.1016/j.jhydrol.2010.11.014, 2011.

Di, Z. H., Xie, Z. H., Yuan, X., Tian, X. J., Luo, Z. D., and Chen, Y. N.: Prediction of water table depths under soil watergroundwater interaction and stream water conveyance, Sci. China Earth Sci., 54, 420-430, doi:10.1007/s11430-010-4050-8, 2011.

Fan, Y.: Groundwater in the Earth's critical zone: Relevance to large-scale patterns and processes, Water Resour. Res., 51, 30523069, doi:10.1002/2015WR017037, 2015.

Fan, Y. and Miguez-Macho, G.: Potential groundwater contribution to Amazon evapotranspiration, Hydrol. Earth Syst. Sci., 14, 2039-2056, doi:10.5194/hess-14-2039-2010, 2010.

Fan, Y. and Miguez-Macho, G.: A simple hydrologic framework for simulating wetlands in climate and earth system models, Clim. Dynam., 37, 253-278, doi:10.1007/s00382-010-0829-8, 2011.

Fan, Y., Miguez-Macho, G., Weaver, C. P., Walko, R., and Robock, A.: Incorporating water table dynamics in climate modeling: 1. Water table observations and equilibrium water table simulations, J. Geophys. Res.-Atmos., 112, D10125, doi:10.1029/2006jd008111, 2007.

Gent, P. R., Danabasoglu, G., Donner, L. J., Holland, M. M., Hunke, E. C., Jayne, S. R., Lawrence, D. M., Neale, R. B., Rasch, P. J., Vertenstein, M., Worley, P. H., Yang, Z. L., and Zhang, M. H.:
The Community Climate System Model Version 4, J. Climate, 24, 4973-4991, doi:10.1175/2011jcli4083.1, 2011.

Hirano, A., Welch, R., and Lang, H.: Mapping from ASTER stereo image data: DEM validation and accuracy assessment, ISPRS J. Photogram. Remote Sens., 57, 356-370, 2003.

Hurrell, J. W., Holland, M. M., Gent, P. R., Ghan, S., Kay, J. E., Kushner, P. J., Lamarque, J. F., Large, W. G., Lawrence, D., Lindsay, K., Lipscomb, W. H., Long, M. C., Mahowald, N., Marsh, D. R., Neale, R. B., Rasch, P., Vavrus, S., Vertenstein, M., Bader, D., Collins, W. D., Hack, J. J., Kiehl, J., and Marshall, S.: The Community Earth System Model A Framework for Collaborative Research, B. Am. Meteorol. Soc., 94, 1339-1360, doi:10.1175/Bams-D-12-00121.1, 2013.

Jobbagy, E. G., Nosetto, M. D., Villagra, P. E., and Jackson, R. B.: Water subsidies from mountains to deserts: their role in sustaining groundwater-fed oases in a sandy landscape, Ecol. Appl., 21, 678-694, doi:10.1890/09-1427.1, 2011.

Kluzek, E.: CESM research tools: CLM4 in CESM1.0.4 user's guide documentation, National Centers for Atmospheric Research, Boulder, 2012.

Li, H., Sun, D., Yu, Y., Wang, H., Liu, Y., Liu, Q., Du, Y., Wang, H., and Cao, B.: Evaluation of the VIIRS and MODIS LST products in an arid area of Northwest China, Remote Sens. Environ., 142, 111-121, 2014.

Li, X., Lu, L., Cheng, G. D., and Xiao, H. L.: Quantifying landscape structure of the Heihe River Basin, north-west China using FRAGSTATS, J. Arid Environ., 48, 521-535, doi:10.1006/jare.2000.0715, 2001.

Li, X., Nan, Z., Cheng, G., Ding, Y., Wu, L., Wang, L., Wang, J., Ran, Y., Li, H., and Pan, X.: Toward an improved data stewardship and service for environmental and ecological science data in West China, Int. J. Digit. Earth, 4, 347-359, 2011.

Li, X., Cheng, G. D., Liu, S. M., Xiao, Q., Ma, M. G., Jin, R., Che, T., Liu, Q. H., Wang, W. Z., Qi, Y., Wen, J. G., Li, H. Y., Zhu, G. F., Guo, J. W., Ran, Y. H., Wang, S. G., Zhu, Z. L., Zhou, J., Hu, X. L., and Xu, Z. W.: Heihe Watershed Allied Telemetry Experimental Research (HiWATER): Scientific Objectives and Experimental Design, B. Am. Meteorol. Soc., 94, 1145-1160, doi:10.1175/Bams-D-12-00154.1, 2013.

Liang, X. and Xie, Z. H.: Important factors in land-atmosphere interactions: surface runoff generations and interactions between surface and groundwater, Global Planet. Change, 38, 101-114, doi:10.1016/S0921-8181(03)00012-2, 2003.

Liang, X., Xie, Z. H., and Huang, M. Y.: A new parameterization for surface and groundwater interactions and its impact on water budgets with the variable infiltration capacity (VIC) land surface model, J. Geophys. Res.-Atmos., 108, 8613, doi:10.1029/2002jd003090, 2003.

Lindsay, K., Bonan, G. B., Doney, S. C., Hoffman, F. M., Lawrence, D. M., Long, M. C., Mahowald, N. M., Moore, J. K., Randerson, J. T., and Thornton, P. E.: Preindustrial-Control and Twentieth-Century Carbon Cycle Experiments with the Earth System Model CESM1(BGC), J. Climate, 27, 8981-9005, doi:10.1175/Jcli-D-12-00565.1, 2014.

Liu, J., Chen, R., Song, Y., Yang, Y., Qing, W., Han, C., and Liu, Z.: Observations of precipitation type using a time-lapse camera in a mountainous region and calculation of the rain/snow proportion based on the critical air temperature, Environ. Earth Sci., 73, 1545-1554, doi:10.1007/s12665-014-3506-0, 2014. 
Liu, S. M., Xu, Z. W., Wang, W. Z., Jia, Z. Z., Zhu, M. J., Bai, J., and Wang, J. M.: A comparison of eddy-covariance and large aperture scintillometer measurements with respect to the energy balance closure problem, Hydrol. Earth Syst. Sci., 15, 1291-1306, doi:10.5194/hess-15-1291-2011, 2011.

Lu, L., Li, X., and Cheng, G. D.: Landscape evolution in the middle Heihe River Basin of north-west China during the last decade, J. Arid Environ., 53, 395-408, doi:10.1006/jare.2002.1032, 2003.

Mao, J., Thornton, P. E., Shi, X., Zhao, M., and Post, W. M.: Remote Sensing Evaluation of CLM4 GPP for the Period 2000-09, J. Climate, 25, 5327-5342, 2012.

Maxwell, R. M. and Kollet, S. J.: Interdependence of groundwater dynamics and land-energy feedbacks under climate change, Nat. Geosci., 1, 665-669, doi:10.1038/Ngeo315, 2008.

Maxwell, R. M., Chow, F. K., and Kollet, S. J.: The groundwater-land-surface-atmosphere connection: Soil moisture effects on the atmospheric boundary layer in fullycoupled simulations, Adv. Water Resour., 30, 2447-2466, doi:10.1016/j.advwatres.2007.05.018, 2007.

Miguez-Macho, G., Fan, Y., Weaver, C. P., Walko, R., and Robock, A.: Incorporating water table dynamics in climate modeling: 2. Formulation, validation, and soil moisture simulation, J. Geophys. Res.-Atmos., 112, D13108, doi:10.1029/2006jd008112, 2007.

Milly, P. C., Dunne, K. A., and Vecchia, A. V.: Global pattern of trends in streamflow and water availability in a changing climate, Nature, 438, 347-350, 2005.

Nepstad, D. C., Decarvalho, C. R., Davidson, E. A., Jipp, P. H., Lefebvre, P. A., Negreiros, G. H., Dasilva, E. D., Stone, T. A., Trumbore, S. E., and Vieira, S.: The Role of Deep Roots in the Hydrological and Carbon Cycles of Amazonian Forests and Pastures, Nature, 372, 666-669, doi:10.1038/372666a0, 1994.

Oleson, K., Lawrence, D., Bonan, G., Drewniak, B., Huang, M., Koven, C., Levis, S., Li, F., Riley, W., and Subin, Z.: Technical Description of version 4.5 of the Community Land Model (CLM), NCAR, National Center for Atmospheric Research (NCAR) Boulder, Colorado, 2013.

Ouyang, Z., Zhao, T., Wang, X., and Miao, H.: Ecosystem services analyses and valuation of China terrestrial surface water system, Acta Ecol. Sin., 24, 2091-2099, 2003.

Qi, S. Z. and Luo, F.: Water environmental degradation of the Heihe River Basin in arid northwestern China, Environ. Monit. Assess., 108, 205-215, doi:10.1007/s10661-005-3912-6, 2005.

Ran, Y., Li, X., Lu, L., and Li, Z.: Large-scale land cover mapping with the integration of multi-source information based on the Dempster-Shafer theory, Int. J. Geogr. Inf. Sci., 26, 169-191, 2012.

Scanlon, B. R., Healy, R. W., and Cook, P. G.: Choosing appropriate techniques for quantifying groundwater recharge, Hydrogeol. J., 10, 18-39, 2002.

Schär, C., Lüthi, D., Beyerle, U., and Heise, E.: The soilprecipitation feedback: A process study with a regional climate model, J. Climate, 12, 722-741, 1999.
Shangguan, W., Dai, Y., Liu, B., Ye, A., and Yuan, H.: A soil particle-size distribution dataset for regional land and climate modelling in China, Geoderma, 171, 85-91, 2012.

Shen, Y. and Chen, Y.: Global perspective on hydrology, water balance, and water resources management in arid basins, Hydrol. Process., 24, 129-135, 2010.

Tachikawa, T., Kaku, M., Iwasaki, A., Gesch, D. B., Oimoen, M. J., Zhang, Z., Danielson, J. J., Krieger, T., Curtis, B., and Haase, J.: ASTER global digital elevation model version 2 - summary of validation results, NASA, 2011.

Tsur, Y. and Graham-Tomasi, T.: The buffer value of groundwater with stochastic surface water supplies, J. Environ. Econ. Manage., 21, 201-224, 1991.

Wang, K., Mao, J., Dickinson, R. E., Shi, X., Post, W. M., Zhu, Z., and Myneni, R. B.: Evaluation of CLM4 solar radiation partitioning scheme using remote sensing and site level FPAR datasets, Remote Sensing, 5, 2857-2882, 2013.

Wu, J. K., Ding, Y., Ye, B., Yang, Q., Zhang, X., and Wang, J.: Spatio-temporal variation of stable isotopes in precipitation in the Heihe River Basin, Northwestern China, Environ. Earth Sci., 61, 1123-1134, doi:10.1007/s12665-009-0432-7, 2010.

Xie, Z. H. and Yuan, X.: Prediction of water table under streamaquifer interactions over an arid region, Hydrol. Process., 24, 160-169, doi:10.1002/Hyp.7434, 2010.

Xie, Z. H., Di, Z. H., Luo, Z. D., and Ma, Q.: A QuasiThree-Dimensional Variably Saturated Groundwater Flow Model for Climate Modeling, J. Hydrometeorol., 13, 27-46, doi:10.1175/Jhm-D-10-05019.1, 2012.

Xie, Z. H., Zeng, N., Wang, H. J., Lin, Z., Tian, X. J., and Jia, B. H.: Past, present and future of the carbon cycle, Natl. Sci. Rev., 1, 18-21, doi:10.1093/nsr/nwt021, 2014.

Yu, Y., Xie, Z. H., and Zeng, X. B.: Impacts of modified Richards equation on RegCM4 regional climate modeling over East Asia, J. Geophys. Res.-Atmos., 119, 12642-12659, doi:10.1002/2014jd021872, 2014.

Zhao, W. and Cheng, G.: Review of several problems on the study of eco-hydrological processes in arid zones, Chinese Sci. Bull., 47, 353-360, 2002.

Zhou, J., Hu, B. X., Cheng, G., Wang, G., and Li, X.: Development of a three-dimensional watershed modelling system for water cycle in the middle part of the Heihe rivershed, in the west of China, Hydrol. Process., 25, 1964-1978, 2011.

Zou, J., Xie, Z. H., Yu, Y., Zhan, C. S., and Sun, Q.: Climatic responses to anthropogenic groundwater exploitation: a case study of the Haihe River Basin, Northern China, Clim. Dynam., 42, 2125-2145, doi:10.1007/s00382-013-1995-2, 2014.

Zou, J., Xie, Z. H., Zhan, C. S., Qin, P. H., Sun, Q., Jia, B. H., and Xia, J.: Effects of anthropogenic groundwater exploitation on land surface processes: A case study of the Haihe River Basin, northern China, J. Hydrol., 524, 625-641, doi:10.1016/j.jhydrol.2015.03.026, 2015. 